\title{
The Real \\ Consequences of Financial Stress
}

\author{
Stefan Mittnik* \\ Willi Semmler**
}

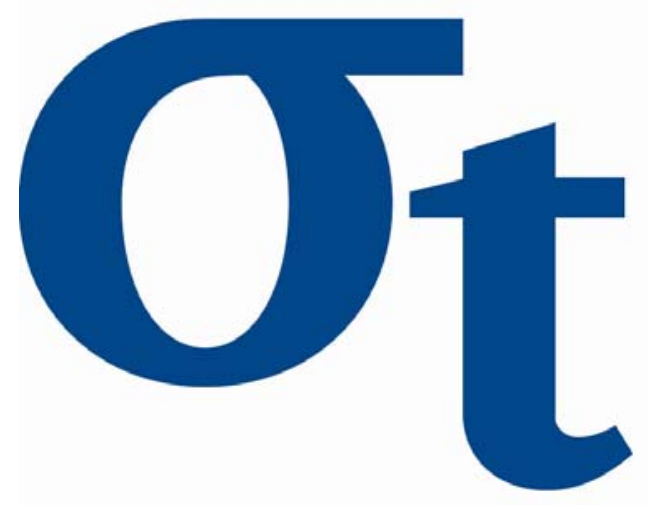

9)

$\forall$

6

m

U

* Ludwig-Maximilians-Universität München, Germany

** New School for Social Research New York, USA

This research was supported by the Deutsche Forschungsgemeinschaft through the SFB 649 "Economic Risk".

http://sfb649. wiwi.hu-berlin.de ISSN 1860-5664 


\title{
The Real Consequences of Financial Stress*
}

\author{
Stefan Mittnik ${ }^{\dagger}$ and Willi Semmler ${ }^{\ddagger}$
}

First version: March 11, 2011; this versions: February 22, 2013

\begin{abstract}
We introduce a dynamic banking-macro model, which abstains from conventional meanreversion assumptions and in which - similar to Brunnermeier and Sannikov (2010) - adverse asset-price movements and their impact on risk premia and credit spreads can induce instabilities in the banking sector. To assess such phenomena empirically, we employ a multi-regime vector autoregression (MRVAR) approach rather than conventional linear vector autoregressions. We conduct bivariate empirical analyses, using country-specific financial-stress indices and industrial production, for the U.S., the UK and the four large euro-area countries. Our MRVAR-based impulse-response studies demonstrate that, compared to a linear specification, response profiles are dependent on the current state of the economy as well as the sign and size of shocks. Previous multi-regime-based studies, focusing solely on the regime-dependence of responses, conclude that, during a high-stress period, stress-increasing shocks have more dramatic consequences for economic activity than during low stress. Conducting size-dependent response analysis, we find that this holds only for small shocks and reverses when shocks become sufficiently large to induce immediate regime switches. Our findings also suggest that, in states of high financial stress, large negative shocks to financial-stress have sizeable positive effects on real activity and support the idea of "unconventional" monetary policy measures in cases of extreme financial stress.
\end{abstract}

Keywords: banking-sector instability, financial stress, monetary policy, nonlinear VAR, regime dependence

JEL classifications: E2, E6, C13

*Previous versions, entitled "Estimating a Banking-Macro Model for Europe Using a Multi-regime VAR," were presented at the 19th Symposium of the Society for Nonlinear Dynamics and Econometrics, 2011; 4th International Conference on Computational and Financial Econometrics, 2011; SEEK Workshop on NonLinear Economic Modelling: Theory and Applications, 2012; and workshops at Humboldt University Berlin and Giessen University, Germany, as well as the Centre Cournot, Paris, BI Business School, Oslo, Monetary Authority of Hong Kong, and the Catholic University, Milano. We thank the participants for valuable comments. We are especially grateful for communications with Markus Brunnermeier and to James Ramsey, Timo Teräsvirta and two anonymous referees for constructive comments, which helped to greatly improve the paper. Part of the research was done while SM was Theodor Heuss Visiting Professor at the New School for Social Research and while WS was Fulbright Visiting Professor at the Vienna University of Economics and Business and visiting the Center of Economic Risk at Humboldt University Berlin, being supported by the German Research Foundation via the CRC 649 Economic Risk. We thank the hosting institutions for their excellent hospitality and the funding organizations for their generous support. WS would also like to thank the Centre for European Economic Research (ZEW) for financial support.

${ }^{\dagger}$ Dept. of Statistics and Center for Quantitative Risk Analysis, Ludwig-Maximilians-Universität München, Akademiestr. 1/I, 80799 Munich, Germany.

${ }^{\ddagger}$ Dept. of Economics, New School for Social Research, 79 Fifth Avenue, New York, NY 10003, USA 


\section{Introduction}

The banking system played a central role in the 2007-08 financial meltdown in the U.S. This phenomenon, as Reinhard and Rogoff (2009) and Gorton (2009, 2010) underscore, is all too common in financial crises and tends exacerbate and amplify the economic downturnwhatever may have caused it. Gorton (2010) points out that whereas in the past loan losses and bank runs have been the conventional mechanisms by which crises where triggered, more recently, banking crises seem to be strongly related to adverse shocks in asset-value losses and financial stress. In the aftermath of this recent "great recession," a number of studies have investigated the effects of financial stress on economic output. He et al. (2008), Brunnermeier (2009), Adrian et al. (2010), Davig and Hakkio (2010), and Hubrich and Tetlow (2011) conduct empirical analyses for the U.S. economy. Monnin and Jokipii (2010) consider several OECD countries; Mallik and Sousa (2011) and Hollo et al. (2012) look at the euro area; and van Roye (2012) focuses on Germany.

Theoretical analyses of the recent meltdown have largely used used the financial accelerator to model the linkage between the financial and the real sector. This strategy is not without problems. Brunnermeier and Sannikov $(2010,2012)$ point out that the destabilizing dynamics are not adequately captured in such a setting. Furthermore, the financial-accelerator theory has been mainly applied to firms and households, so far. Bernanke, Gertler and Gilchrist (1999) show that financial markets can have amplifying effects. In the DSGE tradition, however, there are only locally magnifying effect, namely, through collaterals. Collateral values rise at a high level of economic activity, making credit available and cheap; and the reverse happens at a low level of economic activity.

From a technical viewpoint, DSGE-type models suffer from the fact that the are often solved via linearization about a unique and stable steady state, and amplifying effects occur only with respect to deviations from the steady state. Moreover, they typically do not track debt dynamics. ${ }^{1}$ Departures from the steady state are eventually mean reverting. Although the economy might accelerate, ultimately it will revert back to the steady state. Related empirical analyses are often conducted by means of linear vetor autoregressions (VARs) as in Gilchrist et al. (2009, 2011), Christensen and Dib (2008), and Del Negro et al. (2010).

As the recent meltdown has, however, demonstrated, shocks to banks seem to be destabilizing rather than mean reverting. ${ }^{2}$ Important empirical papers in this context are Brunnermeier

\footnotetext{
${ }^{1}$ Empirically, the debt-to-asset ratio is predicted to fall in booms and to rise in recessions (cf. Gilchrist et al., 2009). Yet, as Geanakoplos (2010) mentions, the empirical measure is distorted through the way the debt-to-asset ratio is measured.

${ }^{2}$ Students of the great depression maintain that credit and the banking sector had quite strong destabi-
} 
(2009) and Brunnermeier and Pederson (2009), who show that financial intermediaries ${ }^{3}$ often have to liquidate their capital, when asset prices fall and margin requirements. This forces financial intermediaries to take a hair cut and to further de-lever, which depresses asset prices even further and, thus, reinforces the downward spiral.

Models attempting to capture such mechanisms often stress that falling asset prices, possibly accompanied by a fire sale of assets, have external effects on the financial sector. The possibility of a downward spiral, then, comes from interconnectedness, interlinkages and contagion. Investigations along these lines began with Greenwald and Stiglitz (1996) and, more recently, continued with Geanakoplos and Farmer (2009), Adrian et al. (2010), Gorton (2010), Geanakoplos (2010), and Brunnermeier and Sannikov (2010, 2011). These studies argue that such dynamics create an endogenously generated jump in risk, which is usually triggered by large changes in asset-price movements.

Much of the recent research states that this process primarily works through the banks' balance sheets. In the first instance, banks may have loan losses that may arise from defaults of firms or households, the foreign sector, or from sovereign debt. On the other hand, large shocks to asset prices and financial stress affect the asset and liability sides of banks' balance sheets, reducing the availability of credit. As the financial stress rises, so will risk premia, repo rates, TED spreads, and other credit spreads. These spillover effects to other intermediaries (as well as to firms and households) create what Brunnermeier and Sannikov $(2010,2012)$ refer to as endogenous risk.

In this paper, we investigate theoretically and empirically the question of how financial stress and economic output interact. Specifically, we study theoretically how destabilizing mechanisms might work in a model that captures linkages between the banking sector and the real sector. Looking at the U.S. and five EU counties, namely, the UK and the four largest euro-zone economies Germany, France, Italy and Spain, we examine to what extent such linkages can be detected and quantified empirically, using country-specific financial stress indices constructed by the IMF and discussed Cardarelli et al. 2009.

Rather than, as Brunnermeier and Sannikov (2010, 2011), emphasizing the role of asset prices and asset-price volatility in downward destabilization, our approach focuses on movements in risk premia and credit spreads. This is motivated by theoretical and empirical studies

lizing effects. Minsky $(1976,1982)$ and Kindleberger and Aliber (2005), for example, regard the credit sector as a significantly amplifying force. The latter view the instability of credit and Minsky the way financing becomes de-linked from collaterals as contributing factors to a downward spiral, once large real or financial shocks occur. This important tradition captures many aspects of the banking-macro link.

${ }^{3}$ This may include Gorton (2010) calls the shadow banking system, i.e., investment firms, brokers and money-market dealers, that has grown sizeably in the last 15 to 20 years. 
which show that factors, such as large asset price falls, rising volatility, higher risk premia, and a run into liquidity, are highly correlated with movements in discount rates. ${ }^{4}$ Yet, as we will show, triggering of downward instability also depends on the constraints imposed on the banking industry, such as on the growth of capital assets (through borrowing) and on payouts, affecting banks' risk taking, equity formation and leveraging. Higher payouts, for instance, may induce more risk taking and risk transfer and, thus, generate higher aggregate risk and risk premia to be paid by all. We will explore the dynamic behavior for different constraints on banks' decision variables.

Our model is in the spirit of Brunnermeier and Sannikov (2010, 2011), however, we introduce model variants, where the amplifying mechanisms might be stronger or weaker. In a version with strong endogenous amplification of risk (greater credit spreads) and less constraints on insiders' payouts and on growth rates of capital assets (leveraging), there is a greater likelihood for instabilities to occur. On the other hand, in a version with little amplification of credit spreads and stricter constraints on payouts and growth rates of capital assets, instability is less likely to arise. By making this distinction, our analysis offers more differentiated results as, for example, compared to Brunnermeier and Sannikov (2010, 2011).

Standard linear econometric models, such as vector autoregressions (VARs), cannot capture the rich dynamic behavior of our model, as it implies that responses to financial shocks are state dependent. In a state of high financial stress with substantial credit spreads, a positive, financial stress-increasing shock may have different effects than a negative, stressreducing, shock. The same shocks occurring in a stage of low financial stress, low credit spreads and, possibly, high economic activity, may have, again, very different implications. To allow for such phenomena, our empirical analysis employs nonlinear, multi-regime VARs (MRVARs). Such models enable us to capture the complex dynamics and to analyze how the economies under investigation respond at different economic states to different types of shocks. To estimate the interactions between financial stress and economic output, we conduct bivariate analyses using industrial production and country-specific Financial Stress Indices constructed by the IMF.

The paper is organized as follows. Section 2 develops a model that reflects the features discussed above. Section 3 describes the numerical solution of the two model variants proposed, using dynamic programming techniques. Section 4 discusses the empirical analysis by describing the data, briefly introducing the MRVAR approach and presenting the empirical findings from VAR and MRVAR response analyses. The results for the U.S. are discussed in

\footnotetext{
${ }^{4}$ The different factors driving discount rates - and, through that, asset prices - are extensively discussed in Cochrane (2011).
} 
Table 1: The basic balance sheet of a bank

\begin{tabular}{c|c}
\hline \hline Assets & Liabilities \\
\hline$p_{t} k_{t}$ & $d_{t}$ \\
& $n_{t}=p_{t} k_{t^{-}} d_{t}$ \\
\hline total assets & total liabilities
\end{tabular}

some detail, those for the five EU countries are summarized. Section 5 concludes.

\section{The Banking Model and Its Dynamics}

In our model we follow Brunnermeier and Sannikov (2010, 2011) (in short, BS), but introduce decision constraints that can lead to varying degrees with which financial crises have amplifying effects. We also differ in the way we solve the model, namely, by applying dynamic-programming techniques.

To model the banking sector, we look at the basic balance sheet of a bank (see Table 1). On the left hand side, we have the assets, $p_{t} k_{t}$, valued at current asset prices, $p_{t}$, and, on the right hand side, total debt, $d_{t}$, and the resulting net worth, $n_{t}=p_{t} k_{t}-d_{t}{ }^{5}{ }^{5}$ The balance sheet comprises the variables that form a bank's decision problem. We assume banks maximize objective function

$$
V(k, d)=\max _{c_{t}, g_{t}} E \int_{0}^{\infty} e^{-\rho t} U\left(c_{t}\right) d t
$$

with the state variables capital stock and debt evolving according to

$$
d k_{t}=\left(\varphi\left(i_{t} / k_{t}\right)-\delta\right) k_{t} d t+\sigma k_{t} d Z_{t}
$$

and

$$
d d_{t}=\left(r_{t} d_{t}-\left(a k_{t}-i_{t}-c_{t}\right)\right) d t
$$

respectively, with $r_{t}$ denoting the interest rate paid on debt. System (1)-(3) defines the model which underlies our analysis.

Along the lines of BS, we presume that there are payouts, bonus payments for executives, which can be viewed to serve the decision makers' consumption stream, $c_{t},{ }^{6}$ which is dis-

\footnotetext{
${ }^{5} \mathrm{BS}(2010)$ state that equity might be split into inside equity, $\alpha\left(p_{t} k_{t}-d_{t}\right)$, and outside equity, (1 $\alpha)\left(p_{t} k_{t}-d_{t}\right)$. In the following, we will not make distinction.

${ }^{6}$ Semmler and Bernard (2012), compiling the bonus payments of the six largest U.S. investment banks, report that bonus payments, as a percent of revenues, went up from roughly $10 \%$ in 2000 to about $35 \%$ in
} 
counted at rate $\rho$. As BS, we take log utility to represent preferences. Next to the consumption stream, investment, i.e., $g_{t}=i_{t} / k_{t}$ in (2), represents the second decision variable. As implied by (3), investments are permitted to be financed by borrowing.

In (2), assets of the financial intermediaries will be increased by investments, $i_{t} / k_{t}$, where function $\varphi\left(i_{t} / k_{t}\right)$ includes adjustment cost and is concave in the argument, and $\delta$ represents the depreciation rate of assets. ${ }^{7}$ The actual gross capital of the bank increases at the rate $i_{t} / k_{t}$. The last term in (2) is the diffusion term in form of a Brownian motion, with $\sigma$ being constant.

According to (3), debt evolves at a rate determined by the excess spending of investment and consumption over capital income, with the latter being linear, i.e., $a k_{t}$. While investments will increase the stock of assets, a high rate of asset purchases will increase debt. The interest rate to be paid on debt, $r_{t}$, includes a risk premium, which is tends to reflect weak balance sheets and, thus, financial strain of a bank. Below, the interest rate will be endogenously determined, reflecting state or time depending risk premia.

Our setup amounts to a standard model of wealth management, as commonly used to study wealth management of financial institutions (see He and Krishnamurthy, 2008). If we replace, in (3), the constant income for a unit of wealth, $a$, by a weighted average of risky and risk-free returns on a wealth fund, then, our system has similarities with those found in the wealthmanagement literature (cf. Semmler et al., 2009). There, however, an explicit equation for the evolution of debt of the financial intermediary, as in (3), is typically missing. This is an innovative contribution of BS $(2010,2011)$ and others. ${ }^{8}$

BS (2010, 2011) specify the growth rate of asset prices as a geometric Brownian motion, namely,

$$
d p_{t}=\mu_{t} p_{t} d t+\sigma_{t} p_{t} d Z_{t}
$$

which is characterized by time varying volatility, $\sigma_{t}$. This can, for example, arise during rapid sales of assets and create endogenous risk. Instead of using asset price movements and varying volatility, we employ time- or state-dependent risk premia and credit spreads to capture such effects.

2007. In its attempts to reforming the regulation of financial markets, the $\mathrm{EU}$ plans to restrict the cash component of bonus payment to $20 \%$ of total bonus payments, with the remaining portion only to be paid out in subsequent years via common stocks. In our model, we ignore such details in the bonus system.

${ }^{7}$ In a recent version, BS (2011) specify a model with capital assets that could be banking capital or real capital. The model is equivalent of there is perfect substitution among them.

${ }^{8}$ See, for example, Hall (2010), who also includes an equation for the evolution of debt. BS (2010) argue that before 2007 financial intermediaries have been encouraged to take on more risk by being able to transfer of risk to outside investors - for example, via CDOs. As a consequence, financial intermediaries had built up debt and, thus, default risk. 
We model debt via the debt-asset ratio, $d_{t} / k_{t},{ }^{9}$ and, as BS $(2010)$, define $\omega=-\left(d_{t} / k_{t}\right)$. Taking log and time derivative, we can write asset-accumulation and debt dynamics by modifying objective function (1), namely, ${ }^{10}$

$$
V\left(\omega_{t}\right)=\max _{\tilde{c_{t}}, g_{t}} E \int_{0}^{\infty} e^{-\rho t} U\left(\tilde{c_{t}}\right) d t
$$

such that

$$
d \omega_{t}=\left[\left(g_{t}-r_{t}-\delta+\sigma^{2}\right) \omega_{t}+a-\tau\left(g_{t}\right)\right] d t-\tilde{c_{t}}+\sigma \omega_{t} d Z_{t},
$$

with the consumption-to-wealth ratio, $\tilde{c}_{t}=c_{t} / k_{T}$, being an new control variable. ${ }^{11}$

Expression $\tau\left(g_{t}\right)$, in (6), represents a convex adjustment cost, which is affecting the size of borrowing to achieve growth rate $g_{t}$. This is modeled by following the capital-adjustmentcost literature. However, only the growth of wealth, $g_{t}$, enters the evolution of assets, $k_{t} .{ }^{12}$

\section{Specifications, Solution Method and Numerical Re- sults}

Clearly, and as stressed by BS (2010, 2011), the dynamics of models of the type (1)-(3) or (5)-(6) cannot not be studied using the usual linearization techniques. First or even second-order Taylor approximations to solve for local dynamics will not adequately capture the global properties of the model. We, therefore, employ the dynamic-programming (DP) approach put forth in Gruene and Semmler (2004) to study the compact version (5)-(6). To do so, we explore the out-of-steady-state dynamics using a coarse grid for a larger region of the state space and gradually refine the grid for smaller regions. DP provides information on the truly global dynamics in a larger region of the state space with little loss in accuracy (see Becker et al., 2007). ${ }^{13}$

In our model versions, the debt-to-asset ratio is the state variable, and the decision variables are the growth rate of assets and payouts for consumption. Moreover, as in Semmler et al.

\footnotetext{
${ }^{9}$ Note that we use stocks of assets and debt, in contrast to Geanokoplos (2010), who uses flows as leverage measure with leveraging being highly positively correlated with booms.

${ }^{10}$ For a similar approach, see also Hall (2010).

${ }^{11}$ A derivation of a dynamic equation in the stochastic case, using Ito's lemma, is given in BS (2010, 2011). Note, in (6), we treat $\delta$ as a constant.

${ }^{12}$ The other expressions in (6) are straightforward derivations from the negative of the growth rate of the debt-asset ratio as stated above.

${ }^{13}$ A short summary of the solution method of a dynamic decision problem, such as (5)-(6), is given in Ernst and Semmler (2010).
} 
(2009), time needs to be introduced as a further state variable. For the decision variables, we will impose both loose or tight constraints and, as specified below, will let credit spreads be state- and time-dependent.

\subsection{State-Dependent Credit Spreads and Soft Decision Constraints}

We first study a model variant with state-dependent credit spreads and soft decision constraints. One issue in the financial-accelerator theory has been that, relative to empirical evidence, the state-dependent risk premium is too small. To better match the data, Nolan et al. (2009) and Gilchrist et al. (2011) have introduced shocks on risk premia that exhibit strong persistence and increase the financial accelerator effect.

To specify two regimes of low and high risk premia - and, thus, two credit-spread regimesone can define credit spreads as a nonlinear function of leveraging, $\omega_{t}$. To do this, in continuous form, we define credit spreads via

$$
r_{t}=\kappa \arctan \left(\omega_{t}\right)
$$

The $\arctan (\cdot)$ function, with $\kappa>0$, avoids the extreme instabilities arising in the asset-priceleveraging dynamics as might be implied in Geanokoplos (2010) and BS (2010, 2011). In our DP algorithm, we restrict ourselves to the simplest case where banks pay risk premium according to (7). ${ }^{14}$ Banks face credit spreads that rise as the leverage increases. Thus, decisions on consumption and asset growth indirectly depend on state-dependent credit spreads that financial intermediaries are exposed to (cf. Gruene and Semmler, 2004).

Payments ${ }^{15}$ can be tightly of loosely constrained. BS (2010, p. 17) already conjecture that, when bonus payouts are less constrained, "the system is relatively stable near its 'steady state' ... but becomes unstable below the steady state ..."

In the first version of our model, we impose soft decision constraints. When defining the payout, $\tilde{c_{t}}$, we restrict the choice to the interval $\tilde{c_{\min }}<\tilde{c_{t}}<\tilde{c_{\max }}$. Thus, payouts are always positive, but constrained. ${ }^{16}$ For the case of less constrained payouts, we set $0.01<\tilde{c_{t}}<0.3$. Moreover, we constrain the growth of assets to $-0.1<g_{t}<0.1{ }^{17}$

\footnotetext{
${ }^{14}$ Specification (7) makes credit spreads endogenous, but not without bounds. The arctan function for the risk premium has a lower limit, the risk-free rate, as well as an upper limit.

${ }^{15}$ Constraints on the growth rate of assets (or certain types of assets) acquired by banks, are harder to impose, unless there are borrowing constraints introduced, as Geanokoplos (2010) seems to suggest.

${ }^{16}$ Note that we also could allow for dividend payments, as the model can encompass dividend payments.

${ }^{17}$ We do not elaborate on the origin of these constraints, i.e., whether they are imposed by the regulator or self-imposed. We only explore the effects of different constraining rules.
} 


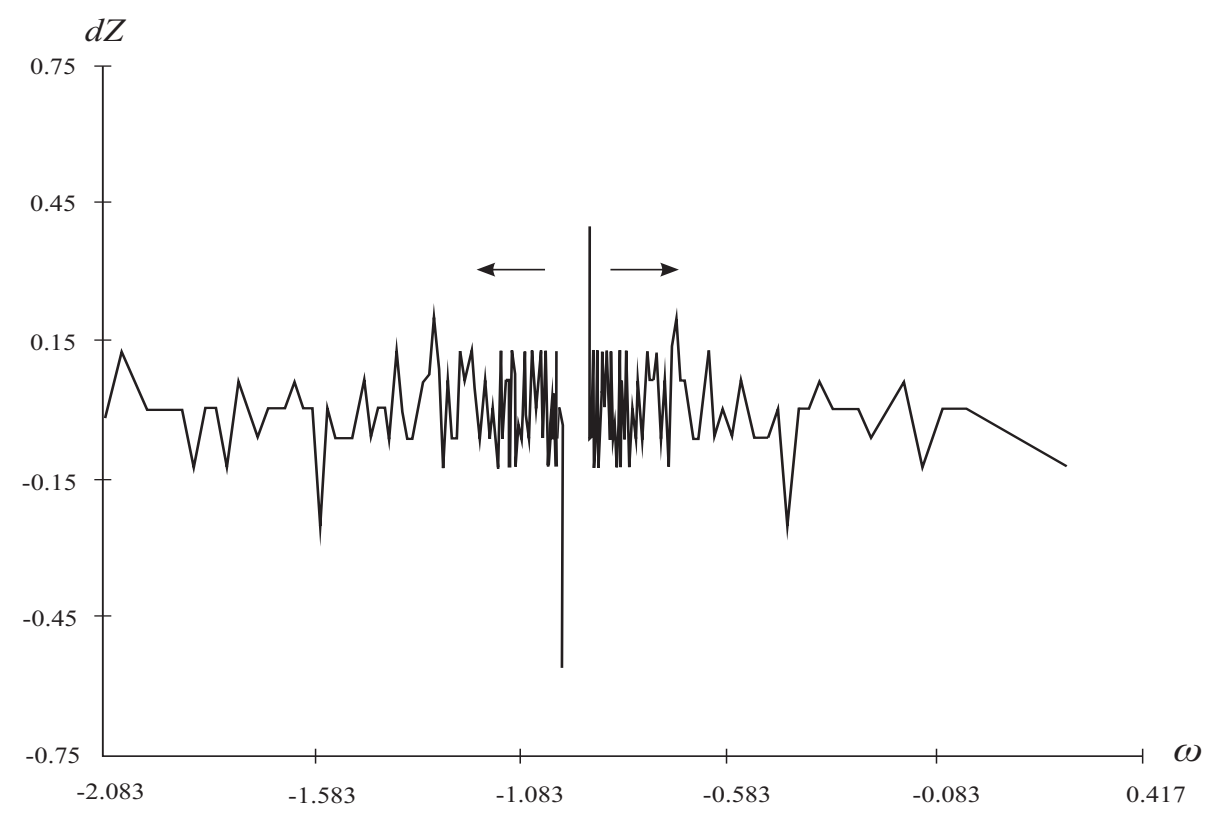

Figure 1: State-dependent credit spread, large payouts, and small domain of attraction

BS (2010, p. 32) state that allowing the debt-to-asset ratio rise too much - as a result of intermediaries' incentives to take on risk for the sake of high (short term) payouts - may induce downturns. In their view, downturns in financial, product and labor markets and higher asset-price volatility result from the fact that externalities are not taken fully into account.

We now present some numerical solutions for the model, reporting first the results for statedependent credit spread and loosely restricted decisions. We parametrize the model as follows: $a=0.25, \alpha=0.3, \sigma=0.008$, and $\rho=0.03$. Note that, given the soft constraints on asset growth and consumption payouts, both together can easily surpass the gross return from assets, $a k_{t}$, quickly generating excessive leverage.

Figure 1 depicts how the debt-asset ratio, $d_{t} / k_{t}$, shown on the horizontal axis, reacts to stochastic shocks, $d Z_{t}$, shown on the vertical axis, with the standard deviation set to $\sigma=$ 0.008. The path of $\omega$ varies in the state space and there is no unidirectional vector field; i.e., the path of $\omega_{t}$ is not a straight line. For low values of the debt-asset ratio, the numericalsolution path in Figure 1 exhibits an unstable steady state at $\omega^{*}=-0.85$. Since zero is a steady state, there is only a small region of attraction.

In other words, small initial leveraging will eventually lead to low or zero debt-asset ratios, because the credit spread is low. A large shock, driving the debt-asset ratio above $\omega^{*}=-0.85$, causes both the leveraging and the credit spread to rise, leading to a vicious 
cycle: higher leverage creates higher credit spreads and higher credit spreads induce higher leveraging. ${ }^{18}$ On the other hand, there is a small domain of attraction: if the financial intermediary starts with low leveraging and low credit spread, both may decrease further.

It is the debt-asset ratio-and the corresponding credit spread-together with the loose restriction of the decision variables that lead to the amplifying behavior. Thus, as predicted in BS (2010), under given conditions, a leveraging ratio beyond a certain threshold is likely to be dynamically unstable. ${ }^{19}$

\subsection{Time-depending Credit Spreads and Stricter Decision Con- straints}

We now turn to the case of a small variation in risk premia and credit spreads and tighter restrictions on the decision variables. As a proxy for time varying in credit spreads, we extract low-frequency components from FSI data. ${ }^{20}$ By doing so, we smooth extremes and tend obtain less erratic dynamics. ${ }^{21}$ In our DP procedure, we would then have one additional state variable, such as

$$
d x=1 d t
$$

a time index that captures the time varying risk premia. The low-frequency components in the credit spread is indexed on $x$, representing time in the DP algorithm. It can be computed and included in our numerical procedure, so that, in (3) or (6),

$$
r_{t}=r_{x}(x)
$$

Formally, the stochastic, dynamic decision problem now has two decision variables and three state variables, the leverage ratio, $\omega_{t}$, the time index, $x_{t}$, and the stochastic shock term, $d Z_{t}$, with $r_{t}$ being time varying.

BS (2010, p. 32) state that limiting payouts should be welfare improving, arguing that “... a regulator can improve social welfare by a policy that limits bonus payments within the

\footnotetext{
${ }^{18}$ Here, we do not address the question at what leverage ratio bankruptcy might occur. This depends on the distance to default, which is defined in the KMV model by the standardized distance of the bank's asset value to its debt level. This is issue is pursued in Gruene and Semmler (2005).

${ }^{19}$ Since the shape of the value function for this case is similar to the next case, it will be discussed in sect. 3.2 .

${ }^{20}$ Credit spreads, such as the BAA/AAA spread and the BAA/T-Bill spread, are important FSI components. Spread measures that have been widely used in previous studies (cf. Gilchrist et al., 2009).

${ }^{21}$ Details of computing the time--varying risk premia are given in the appendix.
} 
financial sector. Specifically, suppose that experts are not allowed to pay themselves as long as financial intermediaries are not sufficiently capitalized." This type of regulatory effort would keep the banking sector sufficiently capitalized and, thus, make it more stable. ${ }^{22}$

Regulation could require payouts to be cut, if the ratio of net worth to total assets falls below a certain threshold. In other words, if $\omega=-\left(d_{t} / k_{t}\right) \leqq \varpi$, then payouts are lowered or even set to zero. Payout rules could also be designed so that management has an incentive to reduce leverage, by allowing high payouts only when leverage is lower. ${ }^{23}$ This might be considered as a penalty on risk taking and high leveraging. ${ }^{24}$ With the constraints on decision variables imposed, the dynamics of the debt--wealth ratio are likely to change. ${ }^{25}$

For the case of more tightly constrained payouts, we restrict (negative and positive) growth rates of intermediaries' asset purchases to the interval $-0.1<g_{t}<0.08$ and also constrain the consumption-to-capital ratio to $0.01<\tilde{c_{t}}<0.18$. Both choices are optimal, but they are constraints. Given these constraints, growth of capital assets and consumption payouts is less likely to exceed the return on capital, $a k_{t}{ }^{26}$

Figure 2 shows that, compared to the looser specification, the domain of attraction is increased, with the steady state, now roughly at $\omega^{*}=-3.9$, being a repeller: with lower asset growth and lower payouts, the debt-to-asset ratio will go to zero. The domain of attraction of the zero debt-to-asset ratio is considerable larger. The potential for large externalities, financial stress and meltdowns are reduced. An initial debt-to-asset ratio to the right the threshold, $\omega^{*}=-3.9$, given stricter constraints and time varying risk premia, will always preserve stability. And a high debt-to-asset ratio can be stabilized, if risk premia and payouts are small. ${ }^{27}$

\footnotetext{
${ }^{22}$ A similar view is present in the Geneva Report (2009, Section 6.2 and the Basel III guidelines.

${ }^{23}$ This has been suggested, for example, by the Financial Stability Board (2009, p. 3): "For significant financial institutions, the size of the variable compensation pool ... should take into account the full range of current and potential risks ..."

${ }^{24}$ BS (2010) argue higher bonus payouts may encourage more risk taking and risk transfer, generating eventually higher aggregate risk and greater risk premia.

${ }^{25}$ One could consider further modifications that take into account the availability of funds from households and from capital inflows, see Caballero and Krishnamurthy (2009). There was also a particular inflow of funds from Central Banks, as in the U.S. in the years 2008 and 2010, when the Fed conducted its unconventional quantitative-easing policies, i.e., buying bad and rapidly declining assets from financial intermediaries. The ECB provision of a three year low interest rate liquidity for EU banks starting in December 2011 and the recent purchase of sovereign bonds is are similar cases. All this has a mitigating effect on the unstable forces generated by the banking system. On the other hand, the precautionary motives of households (and firms) and a "flight to high quality assets" lead to a reduction of financial funds for financial intermediaries.

${ }^{26}$ U.S. regulatory effort have considered to lower the limit on the asset-to-equity ratio from $33 \%$ to $12 \%$, as Basel III intends. Our second model specification is more in line with stricter constraints on the assetto-equity ratio.

${ }^{27}$ In Figure 2, the shocks, $d Z_{t}$, are drawn from the range $-0.1<d Z_{t}<0.1$, and we have $-10<\omega_{t}<0$.
} 


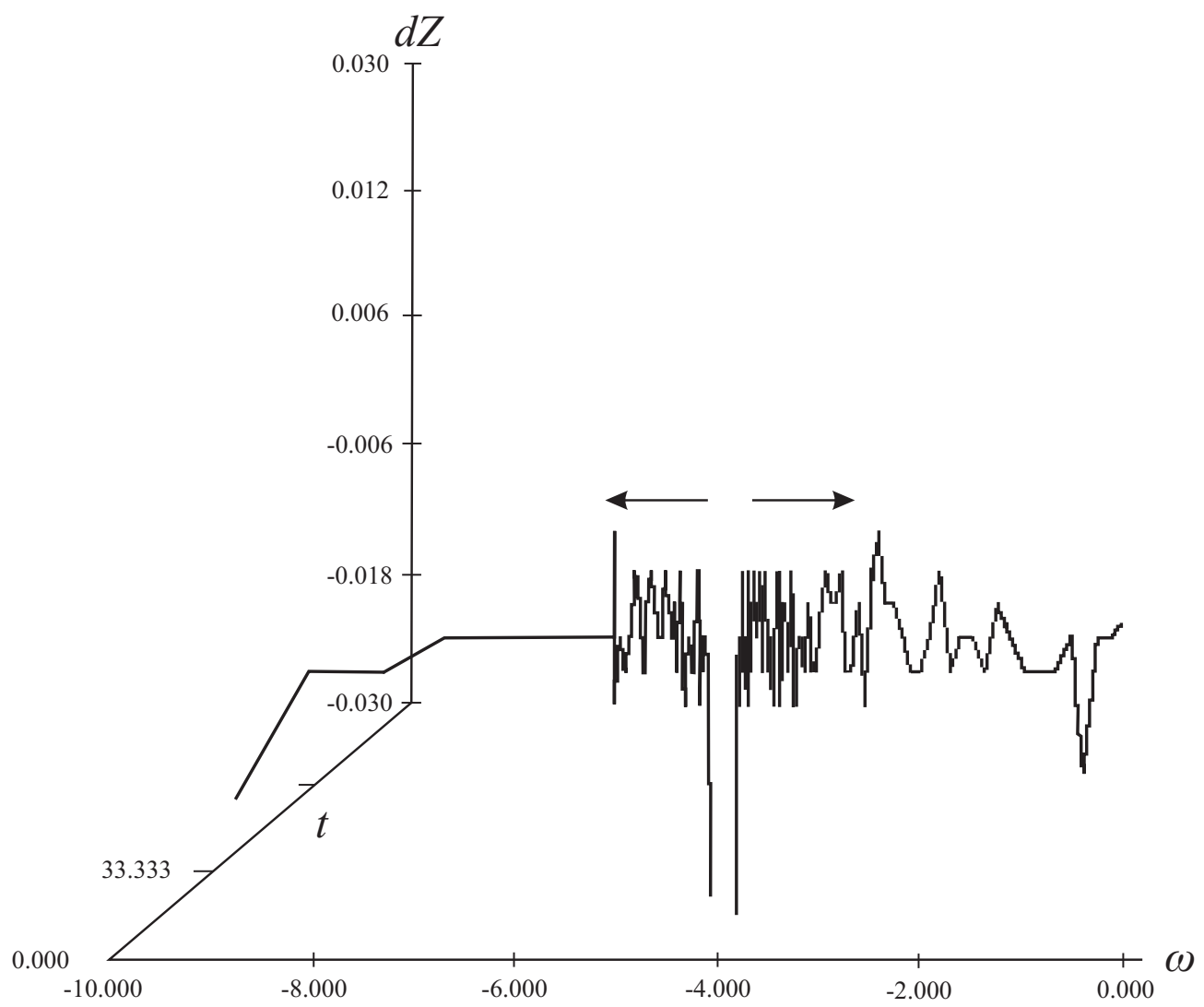

Figure 2: Time-varying credit spread, small payouts and large domain of attraction

Figure 3, showing the corresponding value function, reveals that total welfare (for the financial intermediaries) is rising with lower debt-to-asset ratios. The rise of the value function to the right of the steady state is reasonable, since the welfare from lower credit spreads should be higher. ${ }^{28}$

In both model specifications, the risk premium, and thus the credit spread, are state and time dependent. It is the state dependency of the credit spreads and the softer constraints that are likely to trigger a vicious cycle. In the more restrictive setting, we observe a much larger domain of the zero attractor of the debt-to-asset ratio. Thus, larger shocks are less consequential than in the less restrictive case. The downward instability depends not only on the level of financial stress - and, thus, the size of the risk premia - but also on the constraints of the decision variables.

For the third dimension, the time index $x_{t}$, we specify $0<t<100$. The graph, because we have movements in a three-dimensional space (reflected by the additional time axis), shows the trajectory for a fixed $t$.

${ }^{28}$ The value function corresponding to Figure 1 looks similar and also increases with the debt-to-asset ratio falling, i.e., $\omega$ moving to the right of -0.85 . Note that the shape of the value function is roughly the same as shown in BS (2010) in their Figure 7, though we have negative values on the vertical axis, as we use $\log \tilde{c_{t}}$ rather than $\tilde{c_{t}}$ in the preferences. 


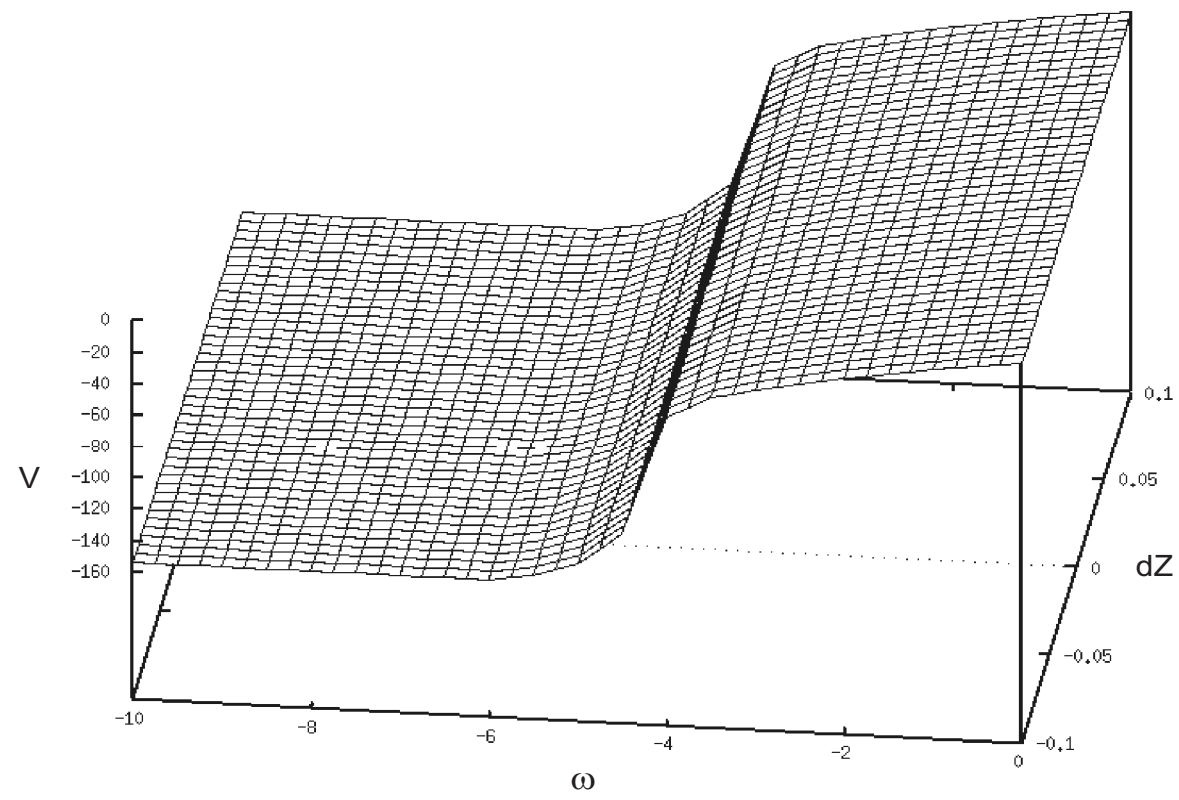

Figure 3: Value function for time-varying credit spread, small payouts, and large domain of attraction

The two specification could be interpreted as two different types of banking systems, which are (in the first case) more or (in the second case) less prone to experience instabilities. As a consequence, the reaction of the two systems to financial shocks may be quite different. Analogously, the success of policy measures, designed to stabilize an ailing financial sector and to avoid or revert negative real consequences, will depend on the specific characteristics of the banking system.

In the following section, we report on the results of an empirical multi-country study that allows for the possibility of complex financial-sector dynamics and the interactions between financial stress and real activity. To address these questions, we employ multi-regime VARs and response-analysis techniques.

\section{Empirical MRVAR Analysis}

In order to investigate the empirical empirical evidence for the possibility of banking sectors being characterized by smaller and larger domains of attraction, we study the stability properties for six countries, the U.S. and the five largest EU economies. Specifically, we will examine whether the data support the single-regime, linear VAR specification for the six countries, or whether they favor the nonlinear MRVAR hypothesis, which implies the 
existence of varying domains of attraction and state-dependent dynamics. Before doing so, we discuss our variable choices for measuring financial stress and output.

\subsection{Empirical Measures for Real Activity and Financial Stress}

Our measure for real activity is dictated by the data frequency chosen for the empirical analysis. To investigate short-, medium- and longer-term effects, our study is based on monthly data, so that the growth rate of industrial production (IP) becomes a "natural" proxy for real activity. The fact that, in some cases, the relative size of the industrial sector differs substantially from country to country may result in country-specific heterogeneity in our empirical finding.

The discussion in the previous section may suggest the leverage ratio to be a trigger-variable for banking instability. However, it can be questioned whether the ratio of net worth to capital assets, or its reciprocal, the degree of leveraging, $\omega$, represents an appropriate measure of financial stress, as it is greatly affected by the way markets valuate assets and liabilities. The valuation of assets is typically the result of their income-stream estimates and presumed discount rates. Similarly, the valuation of liabilities, such as bonds or short- and long-term loans, is strongly affected by their respective risk premia. ${ }^{29}$ Moreover, various forms of credit constraints - measured, for example, by the Fed index of changes in credit standards to determine the ease and tightness of obtaining credit as well as default premia, credit spreads and short term liquidity - represent stress factors for financial intermediaries.

As all these factors potentially affect the credit demand and supply of financial intermediaries, a more comprehensive measure than simply leverage appears to be called for. Therefore, in our empirical analysis we employ the IMF's financial stress index (FSI), which are consistently constructed for a large number of advanced and developing countries (see Caradelli et al., 2011). ${ }^{30}$.

The FSI considers three major sources and measures of instability, namely, (i) a bank-related component: a 12-month rolling banking beta and the TED spread; (ii) a securities-related component: a corporate bond yield spread, an inverted term spread, and a monthly stock returns (measured as declines), six-month rolling monthly squared stock returns, and (iii) an exchange rate component: a six-month rolling monthly squared change in real exchange rates.

\footnotetext{
${ }^{29}$ This is implicit in Merton's risk structure of interest rates, Merton (1974).

${ }^{30} \mathrm{~A}$ variety financial stress indicators have been developed in recent years. Kliesen et al. (2012) analyze and compare eleven alternative measures for the U.S. that are constructed from different subsets of altogether 109 fundamental variables. See also Illing and Lui (2006) and Hatzius et al. (2010)
} 

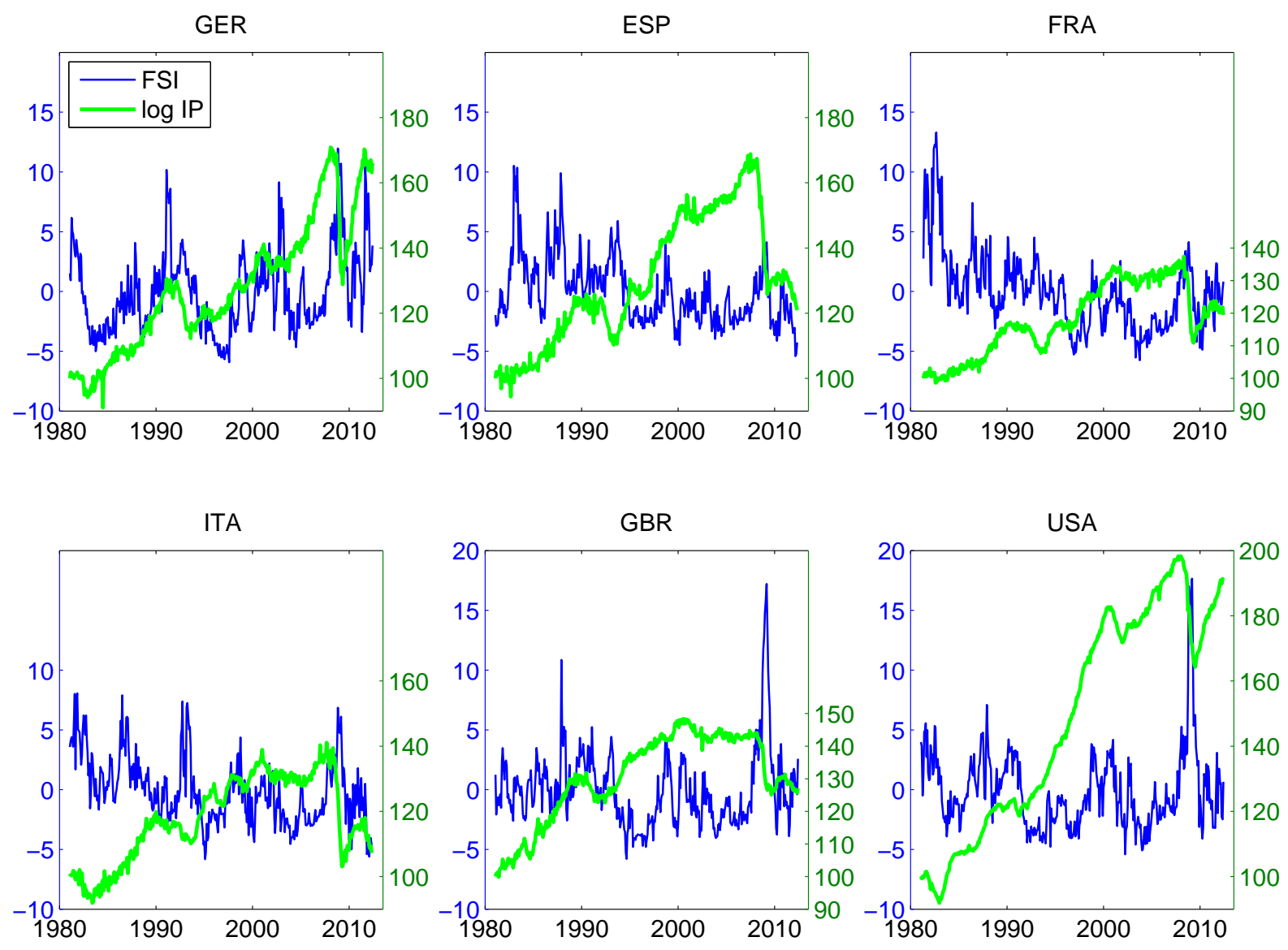

Figure 4: Time series of financial stress (dark line, left scale) and scaled industrial production (light line, right scale)

Figure 4 plots the FSI and (scaled) IP series, starting December 1980, for the four large euro area countries Germany, Spain, France and Italy as well as Great Britain and the U.S. The graphs reveal an inverse relationship between FSI and IP. Especially when financial stress exhibits sudden large positive spikes, IP tends to drop. More generally, we observe that, in general, low financial stress and a well-performing real-sector coincide. ${ }^{31}$ Given the apparent relationship between financial stress and economic activity, we also expect a strong linkage between net worth of financial intermediaries and economic activity, as financial stress affects their balance sheets.

To further assess the relationship between industrial production and financial stress, we conduct (linear) Granger-causality tests for the six countries. The results reject the hypothesis

\footnotetext{
${ }^{31}$ This coincides with the empirical study in Gorton (2010) that insolvency rates of financial institutions increase in bad times.
} 
Table 2: $p$-values from Granger-causality tests between IP growth and FSI

\begin{tabular}{c|cc}
\hline Country & IP $\rightarrow$ FSI & FSI $\rightarrow$ IP \\
\hline GER & 0.0001 & 0.4986 \\
ESP & 0.8074 & 0.0778 \\
FRA & 0.0128 & 0.0709 \\
ITA & 0.0184 & 0.0707 \\
GBR & 0.0036 & 0.1574 \\
USA & 0.0000 & 0.0006 \\
\hline
\end{tabular}

"IP growth does not Granger-cause FSI" (first column in Table 2) in five out of six cases with $p$-values below 0.02 , with Spain being the sole exception $(p=0.8074)$. For the reverse hypothesis, i.e., "FSI do not Granger-cause IP growth" (second column in Table 2) all $p$ values exceed 0.05 , except that for the U.S. $(p=0.0006)$. However, with values ranging from 0.07 to 0.08 , the results for the southern EU countries France, Italy and Spain are somewhat more borderline.

The results on Granger causality should be regarded here as a descriptive tool that summarizes correlational, i.e., linearly approximated, relationships. In view of the strong evidence against the linearity assumptions reported below, the results have to be interpreted with caution.

\subsection{MRVAR Approach}

Linear VAR models have been frequently used to study the financial accelerator. ${ }^{32}$ Such "single-regime VAR" analyses may be suitable for studying the local behavior of between variables affected by infinitesimal disturbances. They are, however, not expected to provide meaningful insights into consequences of large shocks, nor do they allow for state-dependency in shock responses or asymmetric effects to positive and negative shocks. Similarly, so-called "corridor stability," as discussed in the earlier literature on Keynesian macro dynamics (cf. Dimand, 2005; Bruno and Dimand, 2009) and also referred to in the context of financialmarket regulation (cf. Schinasi, 2005) - i.e., situations where small shocks have only small effects but larger shocks could have large, destabilizing effects - cannot be handled in conventional VAR specifications.

\footnotetext{
${ }^{32}$ Christensen and Dib (2008) estimate financial accelerator for the macroeconomy with a linear VAR. For the application of the financial accelerator to study financial intermediaries in a linear VAR setting, see Hakkio and Keeton (2009) and Adrian et al. (2010).
} 
To address such questions empirically, we require a more general modeling framework that can accommodate varying dynamic patterns. The multi-regime vector autoregression (MRVAR $)^{33}$ approach we adopt permits us to detect the presence of multiple regimes and to investigate regime-dependence in the responses to shocks to the system. Shocks might occur during a regime with great instability, as, for example, in the case of a high leverage ratio (or high stress) discussed in Section 3 (see Figure 1) the effects will be larger as compared to a regime with a large domain of attraction and low leverage (and low stress), see Figure 2. As a consequence, responses to positive and negative shocks may not be sign-symmetric and different shock sizes may lead to nonproportional response patterns.

To allow for such phenomena, we generalize the linear, constant-parameter VAR specification in the "mildest" form and adopt a piecewise linear VAR, such as Markov-switching autoregressions (Hamilton, 1989) or threshold autoregressions (Tong, 1978, 1983). A characteristic of Markov-switching autoregressions is that the states are unobservable and defined by some combination of the endogenous variables, so that they do not necessarily have an obvious interpretation. Also, a given observation cannot directly be associated with any particular regime. Only conditional probabilistic assignments are possible via statistical inference based on past information.

For our purposes, namely state-dependent response analysis, states are associated with specific levels of financial stress. MRVAR models in the form of threshold autoregression models of Tong $(1978,1983)$ or, in a vector setting, of multivariate threshold autoregressions (Tsay, 1998) are obvious candidates. In contrast to Markov-switching autoregressions or standard multivariate threshold autoregressions, our approach assumes that we can, based on some observable variable, define upfront a set of interpretable regimes, which are not a result of some estimation procedure, but rather motivated by the objective of the empirical analysis.

The threshold-based MRVAR approach is a simple and parsimonious strategy for nonparametric function estimation and for modeling multi-equilibria settings (Hansen, 2000). It is particularly suitable for our analysis, where we are interested in evaluating the potential effectiveness of policy measures for specific, observable states of the economy, in our case high-stress and low-stress states, which we can explicitly specify by defining threshold variables and, possibly, threshold levels.

\footnotetext{
${ }^{33}$ For an MRVAR-modeling application see also Mittnik and Semmler (2012) and Ernst et al. (2010).
} 
The MRVAR specification we adopted below is given by

$$
y_{t}=c_{i}+\sum_{j=1}^{p_{i}} A_{i j} y_{t-j}+\varepsilon_{i t}, \quad \varepsilon_{i t} \sim\left(0, \Sigma_{i}\right), \quad \text { if } \tau_{i-1}<r_{t-d} \leq \tau_{i}, \quad \text { for } i=1, \ldots, M
$$

where $r_{t-d}, d>0$, is the value of the threshold variable observed at time $t-d$; and regimes are defined by the threshold levels $-\infty=\tau_{0}<\tau_{1}<\cdots<\tau_{M}=\infty$. In the following analysis we estimate a two-regime VAR, with the FSI as threshold variable and the threshold level being estimated by minimizing the corrected AIC (AICc) model-selection criterion.

Response analysis for linear VAR models is straightforward. Point estimates and asymptotic distributions of shock response can be derived analytically from the estimated VAR parameters (cf. Mittnik and Zadrozny, 1993). In nonlinear settings, this is, in general, not possible, and one typically has to resort to Monte Carlo simulations. Following Koop et al. (1996), the so-called generalized impulse responses, which depend on the overall state, $z_{t}$, the type of shock, $v_{t}$, and the response horizon, $h$, are defined by $G I R_{h}\left(z_{t}, v_{t}\right)=$ $\mathrm{E}\left(y_{t+h} \mid z_{t}, u_{t}+v_{t}\right)-\mathrm{E}\left(y_{t+h} \mid z_{t}, u_{t}\right)$, where the overall state, $z_{t}$, reflects the relevant information set. For a Markov-switching VAR process, $z_{t}$ comprises information about the past realizations of $y_{t}$ and the states; for an MRVAR, only information about past realizations $y_{t-1}, \cdots, y_{t-p_{\max }}$, with $p_{\max }=\max \left(p_{1}, \ldots, p_{M}\right)$, is required.

To understand the regime-specific differences in the dynamic characteristics, within-regime response analysis, as in Ehrmann et al. (2003), are helpful. This assumes that the process remains in a given regime for the next, say, $h$ periods and amounts to conducting standard VAR-type response analysis for each regime estimated. Within-regime response analysis can also be viewed as a study of the local dynamic behavior, as shocks need to be sufficiently small for the system not to jump to another regime for the next $h$ periods.

\subsection{Estimation}

We conduct bivariate analyses for the six countries shown in Figure 4, using monthly IP growth and IMF's stress index data from 1981 to 2012. ${ }^{34}$ Specifically, we estimate standard VAR and MRVAR models for the IP-growth rate and FSI levels, defining $y_{t}=$ $\left(100 \Delta \log I P_{t}, F S I_{t}\right)^{\prime}$. For the MRVARs, we specify FSI as the regime-defining threshold variable, as is also done in Hollo et al. (2012), setting the delay parameter in (10) to $d=1$. This allows us to fit the dynamics according to an economy's state of financial stress and to

\footnotetext{
${ }^{34}$ We use seasonally-adjusted industrial-production data from the OECD (2012); the FSI data were provided from the IMF (2011). See Table 3 for the country-specific sample periods.
} 
assess, for example, the effectiveness of policy measures intended to boost real activity by lowering financial stress.

Model selection for the MRVAR specification (10) can be done using the AIC

$$
A I C\left(M, p_{1}, \ldots, p_{M}\right)=\sum_{i=1}^{M} A I C_{i}
$$

where

$$
A I C_{i}=T_{i} \ln \left|\hat{\Sigma}_{i}\right|+2 n\left(n p_{i}+\frac{n+3}{2}\right) ;
$$

and $M$ is the number of regimes; $p_{i}$ is the autoregressive order of regime $i ; T_{i}$ reflects the number of observations associated with regime $i ; \hat{\Sigma}_{i}$ is the estimated residual covariance matrix for regime $i$; and $n$ denotes the number of variables in vector $y_{t}$. Formulation (11) differs from that in Chan et al. (2004) in that we account for possible heterogeneity in the constant terms, $c_{i}$, and residual covariance, $\Sigma_{i}$, across regimes. ${ }^{35}$

Alternatively, Wong and Li (1998) suggest the use of the corrected AIC (in short, AICc), which tends to give more parsimonious specifications and is obtained by modifying (11) via

$$
A I C c\left(M, p_{1}, \ldots, p_{M}\right)=\sum_{i=1}^{M}\left(A I C_{i}+\frac{2 k_{i}\left(k_{i}+1\right)}{T_{i}-k_{i}-1}\right)
$$

with $k_{i}=p_{i} n^{2}+n(n+3) / 2$. Based on univariate simulation experiments, Wong and Li (1998) strongly recommend the AICc over both the AIC and the BIC-a recommendation which we follow here.

The model specifications we obtain for the six countries are reported in Table 3. A look at the AICc values suggests that the MRVAR model clearly dominates the linear VAR specification, with AICc differences ranging from 13.6, for Great Britain, up to 48.7, for Germany. Although judging by such difference does not represent a formal test, the widely accepted "rule of thumb" for the AIC (see Burnham and Anderson, 1998) states that there is "essentially no support" for a model when the difference to the minimum AIC is larger than 10.

The estimated - from a goodness-of-fit point of view-optimal threshold levels, $\hat{\tau}$, defining high- and low-stress regimes and, thus, their domains of attraction, vary substantially from

\footnotetext{
${ }^{35}$ When employing (11) to discriminate between an MRVAR and a standard VAR specification (i.e., a single-regime MRVAR), we need to include the $n$ parameters in the intercept vector, $c$, and the $n(n+1) / 2$ parameters in the residual covariance matrix for an equivalent parameter count.
} 
Table 3: Specifications of VAR and MRVAR models

\begin{tabular}{|c|c|c|c|c|c|c|}
\hline & Germany & Spain & France & Italy & UK & U.S. \\
\hline & \multicolumn{6}{|c|}{ VAR } \\
\hline$p$ & 3 & 5 & 3 & 4 & 2 & 4 \\
\hline $\mathrm{AICc}$ & 793.1 & 662.1 & 454.2 & 626.8 & 305.2 & -31.1 \\
\hline \multirow[t]{2}{*}{$T$} & 377 & 376 & 374 & 376 & 377 & 377 \\
\hline & \multicolumn{6}{|c|}{ MRVAR } \\
\hline$\hat{\tau}$ & -1.949 & -2.343 & -0.402 & 1.313 & 2.519 & 3.062 \\
\hline$p_{l o}$ & 2 & 1 & 4 & 4 & 2 & 4 \\
\hline$p_{h i}$ & 3 & 5 & 3 & 1 & 1 & 1 \\
\hline $\mathrm{AICc}$ & 744.4 & 630.4 & 410.0 & 600.7 & 291.6 & -70.1 \\
\hline$T_{l o}$ & 132 & 75 & 192 & 279 & 317 & 327 \\
\hline$T_{h i}$ & 245 & 301 & 182 & 97 & 60 & 50 \\
\hline Sample & $01 / 1981$ & $01 / 1981$ & $04 / 1981$ & $01 / 1981$ & $01 / 1981$ & $01 / 1981$ \\
\hline period & $05 / 2012$ & $04 / 2012$ & $05 / 2012$ & $04 / 2012$ & $05 / 2012$ & $05 / 2012$ \\
\hline
\end{tabular}

country to country. The values for the U.S., the UK and Italy are positive, so that only more extreme, above-average stress periods are classified as high-stress states. For Germany and Spain, we obtain negative threshold estimates, associating most of the sample with with high-stress and only FSI-values below about -2 are treated as low-stress situations. Note that, for each country, the VAR lag lengths and the (maximum) MRVAR lag lengths are identical. The sole exception is France, where $p_{V A R}=3$ and, for the MRVAR, $p_{l o}=4$ and $p_{h i}=3$.

\subsection{Response Analysis for the U.S.}

We now discuss the empirical results for the U.S. in some detail and summarize those for the other countries in Section 4.5. To assess the effects of the linear versus the nonlinear model specification, we first look at the estimates of the cumulative unit-shock responses for the VAR model and then regime-specific responses for the MRVAR model. The latter give an indication for how the system responds to small shocks that do not induce migration to another regime. Then, we move to the more realistic and - for example, for policymaking - more relevant analysis by investigating overall system responses by allowing for regime migration, looking first at unit-shock responses and then at the size-dependency.

For all responses analyses, we assume that a shock to IP simultaneously affects the FSI, whereas IP reacts with a one-period delay to an FSI shock. 

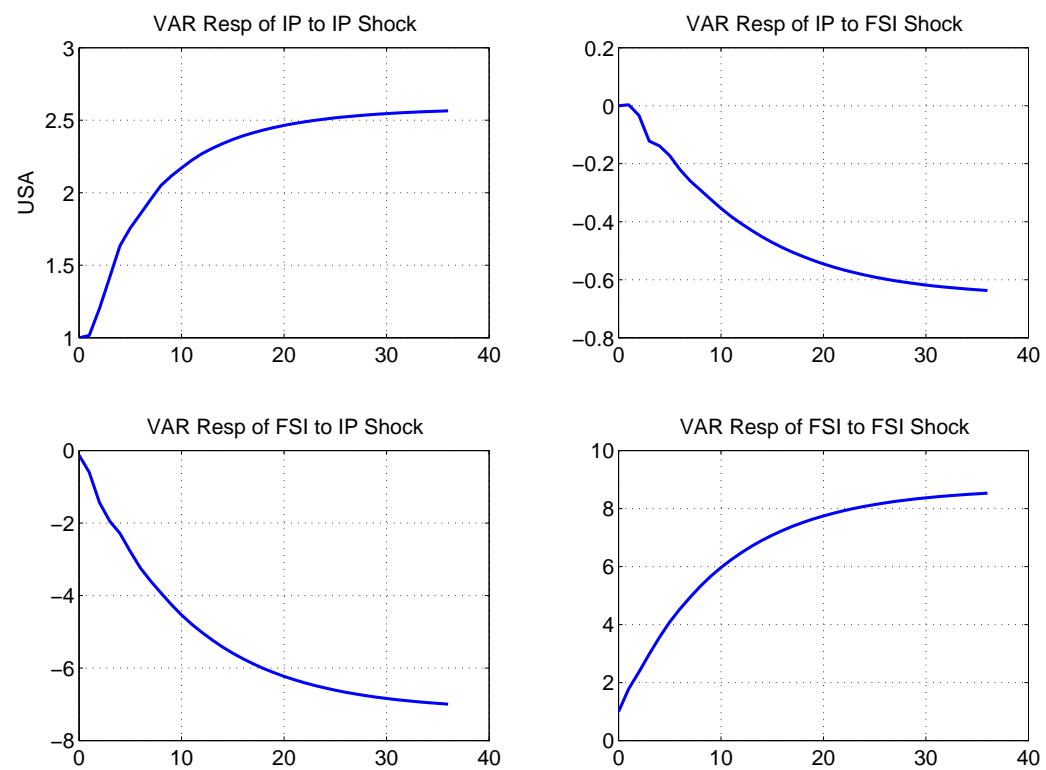

Figure 5: Standard VAR responses for the USA

\subsubsection{Linear VAR Responses}

The cumulative responses due to a unit shock implied by the estimated linear VAR model are shown in Figure 5 over a horizon of 36 month. ${ }^{36}$ The results suggest that, for the U.S., a positive one-standard-deviation stress shock has an increasingly negative effect on IP, which settles at about $-0.65 \%$ after three years. The cumulative response of IP to a unit shock in IP itself settles at 2.6\%; and the stress index responds negatively to a positive IP shock $(-7.2 \%)$, whereas a positive FSI shock lets the index increase $(8.6 \%)$.

\subsubsection{Within-regime MRVAR Responses}

Next, we explore the MRVAR within-regime response behavior. Clearly, the assumption to stay within a particular regime for an extended period is not very realistic as shocks and regime dynamics may induce regime migration. Also, by looking at the within-regime dynamics, we solely focus on the regime-specific autoregressive parameters and ignore the level effects resulting from differences in the regime intercepts. Any differences in the regimes' intercepts will induce additional variation in the overall dynamics when the process switches

\footnotetext{
${ }^{36}$ In the discussion of the general results from the response analysis we focus solely on the responses' point-estimates. We will consider interval estimates when we discuss the results specific to the question under investigation.
} 

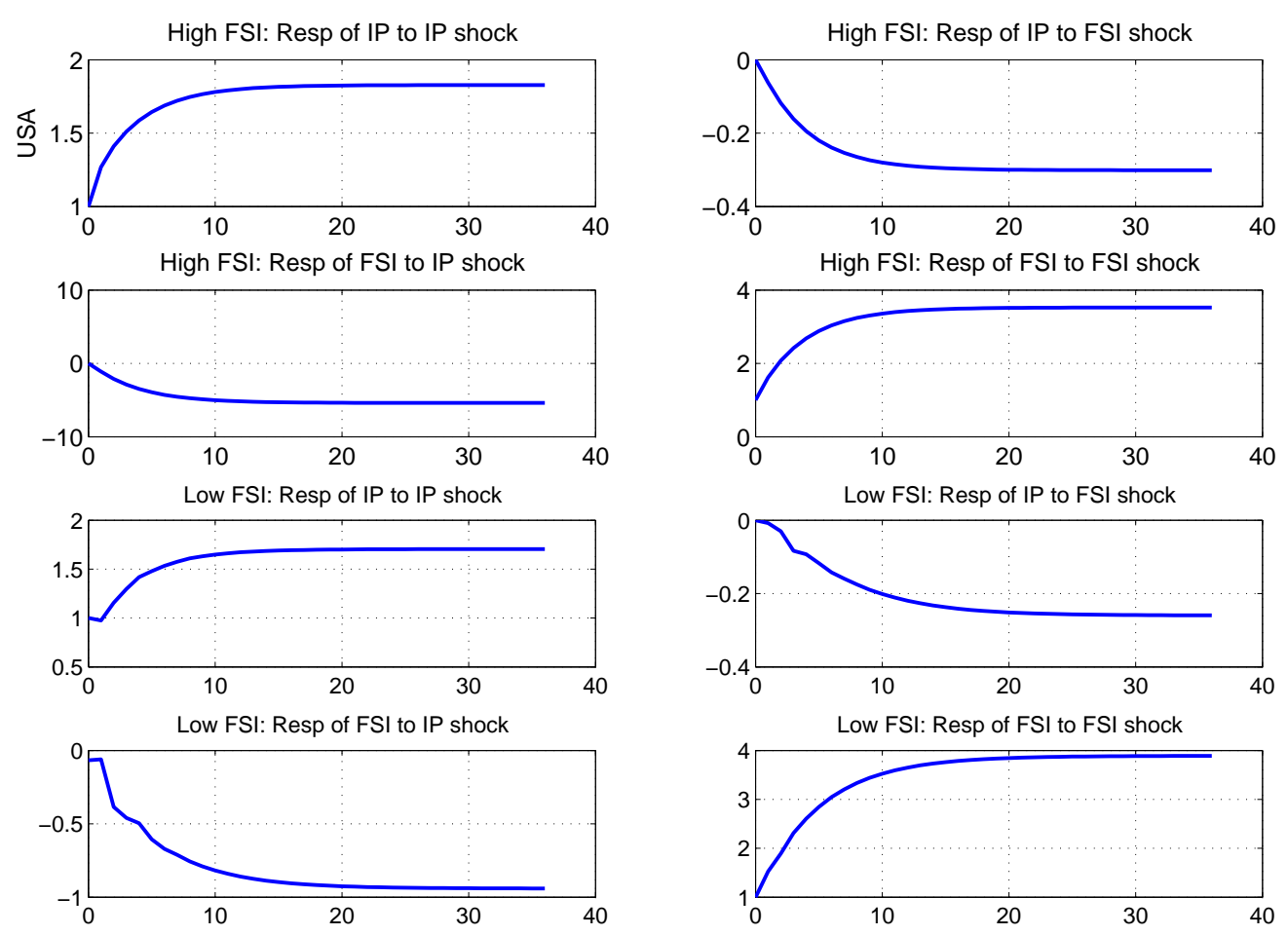

Figure 6: Within-regime responses from MRVAR for USA in high-FSI (top half) and lowFSI regimes (bottom half)

between regimes. However, a regime-specific response analysis is useful as it helps to better understand the short-term dynamics associated with the estimated regimes.

The within-regime MRVAR responses are presented in MRVAR in Figure 6. Here, the cumulative responses to unit-shocks implied for each of the two MRVAR regimes are somewhat different. Within the high-FSI regime (upper half in Figure 6) a positive one-standarddeviation stress shock lowers IP by $-0.30 \%$, which is reached after one year, and amounts to about half of the reduction implied by the linear VAR. Compared to the VAR analysis, at high-FSI, IP responds less positively to a shock to IP itself, settling at $1.8 \%$ rather than 2.6; the MRVAR stress response to a positive IP shock is less negative (-5.4\%); and the cumulative MRVAR response to a positive FSI shock is lower than the VAR-implied estimate (3.5\% versus $8.6 \%)$.

Within the low-FSI regime (lower half in Figure 6) a stress shock has a weak negative impact on IP $(-0.26 \%)$. With $1.7 \%$, the IP response to a positive shock to IP is similar to that during high stress. The stress index responds much less in states of high stress (-0.94 versus -5.4) to a shock in IP; and the cumulative response to an FSI shock is somewhat stronger than 

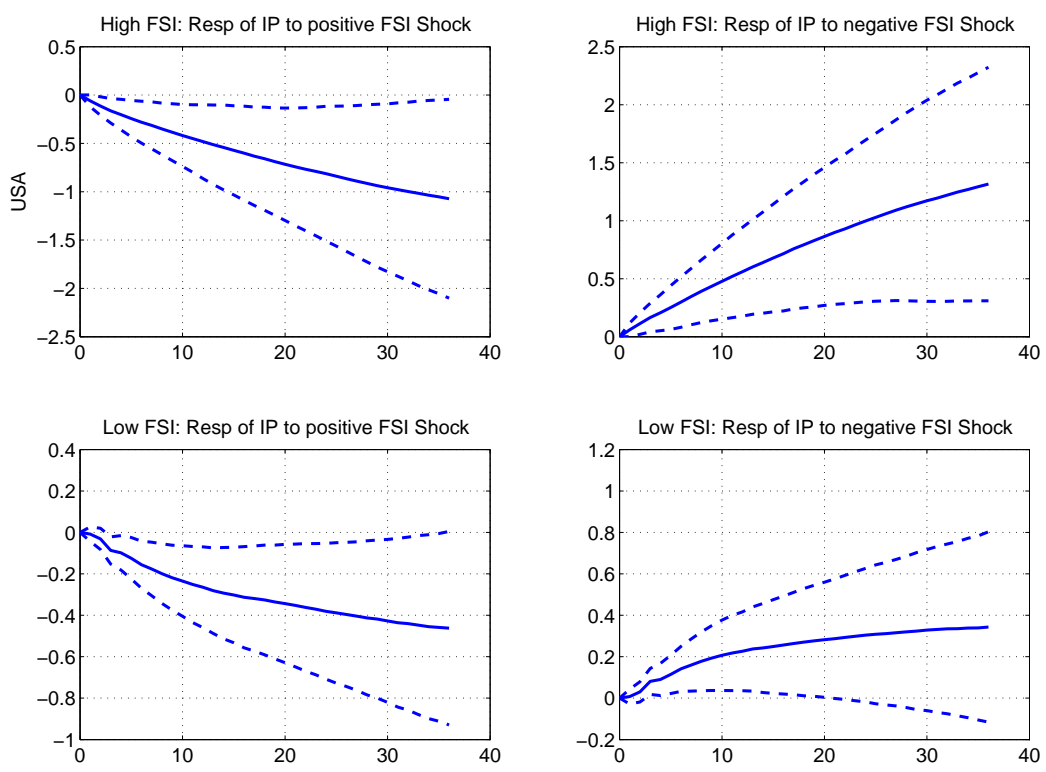

Figure 7: Cumulative MRVAR responses of U.S. IP to positive (left panel) and negative FSI shocks (right panel) in high- (upper panel) and low-stress states (lower panel)

obtained for the high-stress regime (3.9 versus 3.5).

\subsubsection{MRVAR-system Response Analysis to Unit-shocks}

Given our objective, namely the evaluation of the impact of financial sector stress on economic growth, measured in terms of IP growth, subsequent analysis will focus on the response of IP to shocks to FSI. In order to investigate the economy's overall growth effects due to FSI shocks we, first, simulate generalized cumulative response functions to unit shocks, i.e., response functions wthat take the possibility regime migration into account. We do this for specific states at which the shock is assumed to occur. The two specific states we select are the sample averages observed for each of the two regimes, as they can be viewed as typical representatives for low-and high-stress states of the economy. The low-FSI regime-mean is $\bar{y}_{l o}=(0.2372,-1.0127)^{\prime}$, and that for high FSI $\bar{y}_{h i}=(-0.2686,5.5704)^{\prime}$. From these we simulate both a positive and a negative unit-shock to the stress index. The mean cumulative IP responses together with one-standard deviation confidence bands are shown in Figure 7.

One striking difference between the system responses and the linear VAR and within-regime MRVAR responses is that the former have not fully settled after after 36 months, indicating that the system as a whole has more inertia and that shocks have a longer-lived impact than linear response analysis suggests. 
Table 4: MRVAR-implied cumulative IP responses after 36 months due to positive and negative unit-shocks during high- and low-stress states. Note: the corresponding (stateindependent) linear VAR estimates are \pm 0.64 .

\begin{tabular}{l|cc}
\hline & \multicolumn{2}{|c}{ IP response to: } \\
& Positive FSI shock & Negative FSI shock \\
\hline High stress & -1.10 & 1.27 \\
Low stress & -0.47 & 0.34 \\
\hline
\end{tabular}

The estimated unit-shock responses up to a horizon of 36 months, summarized in Table 4, strongly suggest that the impact of an FSI shock on IP varies with financial stress. A positive unit-shock in the average high-stress state (top left plot in Figure 7) causes U.S. IP to drop by about $-1.1 \%$ within three years, after which zero is included in the confidence band. The same shock applied in the average low-stress state (bottom left plot), results in an IP contraction that is less dramatic (-0.43\%) over a three-year horizon, where the confidence band starts to include zero. Thus, in a state where financial stress is already high, an additional unit-increase curbs IP more severely, namely about two and a half times as much, than during calm periods. If, on the other hand, the FSI-unit-shock is negative, we obtain pretty much the reverse results. In absolute terms, a negative FSI unit-shock during high stress (top right plot) has a stronger impact than a positive one stress $(1.27 \%$ vs. $-1.10 \%$ ); with $0.34 \%$, the weakest impact comes from a negative unit-FSI-shock when the stress level is already low. Thus, at least for one-standard-deviation shocks occurring during average high- and low-stress states, U.S. IP responses are strongly state dependent and, to a lesser extent, sign-asymmetric.

\subsubsection{MRVAR-system Responses to Different Shock Sizes}

Next, we investigate to what extent the size of the shock to financial stress matters. In addition to simply assuming a unit shock to the stress index, we simulate the cumulative IP responses to FSI shocks with different sizes. Specifically, we impose positive and negative shocks from one through four standard deviations. ${ }^{37}$ It turns out that the IP responses differ dramatically as the magnitude of the shocks varies. Figure 8 compares the response profiles scaled by the size of the shock; ${ }^{38}$ and Table 5 reports the point estimates of the

\footnotetext{
${ }^{37} \mathrm{~A}$ shock-size of four standard deviations appears rather large. However, the FSI for the U.S. peaked in during the 2008-09 stress period at 17.64, which corresponds to 5.44 standard deviations. Based on the FSI data prior to that period, the peak corresponds to 6.99 standard deviations.

${ }^{38}$ Note that all responses shown in Figure 8 turn out to increase monotonically, so that shocks of size one have the weakest and four-unit shocks the strongest response. This also holds for Figure 9 through 13.
} 

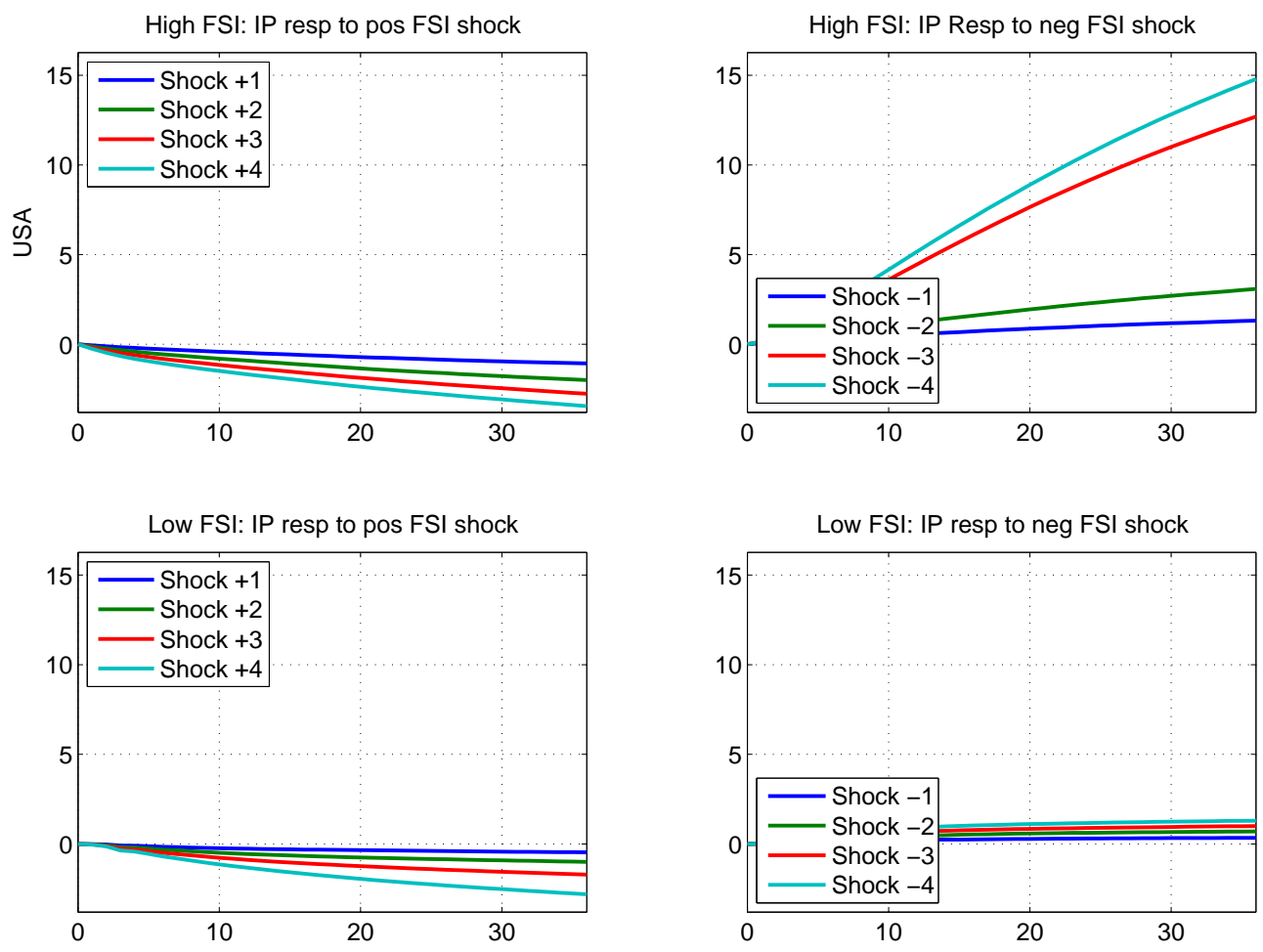

Figure 8: Cumulative MRVAR responses of U.S. IP to negative (top) and positive (bottom) stress shocks in high-(left) and low-stress states (right)

scaled responses after month 36 .

If the economy is financially distressed, stress reduction is an effective measure to induce growth. A reduction of one-unit induces a $1.27 \%$ cumulative increase in IP growth after 36 months (see upper half, last column in Table 5). A negative two-instead of a one-unit shock is relatively more effective, resulting in a 3.05\% increase per shock unit; and, compared to this, a three-unit reduction has a substantially stronger implication with a per-unit boost of 12.71. This increase in relative impact is due to the fact that a stress reduction of this size has very high probability of moving the economy quickly into a low-stress state. We do not observe such a tremendous jump when the shock size grows even further, as the probability of moving right away into the low-stress regime cannot anymore increased by that much.

The potency of negative shock is considerably less in low-than in high-stress periods (lower half, last column, Table 5): one- and two-unit shock have about a quarter, and three- and four-unit shock have less than a thenth of the impact compared to high-stress states.

Positive FSI shocks lower IP in both high- and low-stress states (first column, Table 5). 
Table 5: MRVAR-implied relative cumulative IP responses after 36 months due to positive and negative shocks of different sizes during high- and low-stress states. Note: all response plots are scaled by the shock size and, thus, represent responses relative to unit-shock responses; the corresponding scaled (state- and size-independent) VAR-implied estimates are all \pm 0.64 .

\begin{tabular}{cc|cc}
\hline & Shock & \multicolumn{2}{|c}{ Shock sign } \\
size & Positive & Negative \\
\hline High stress & 1 & -1.10 & 1.27 \\
& 2 & -1.99 & 3.05 \\
& 3 & -2.80 & 12.71 \\
& 4 & -3.67 & 14.83 \\
\hline Low stress & 1 & -0.47 & 0.34 \\
& 2 & -1.02 & 0.72 \\
& 3 & -1.74 & 1.02 \\
& 4 & -2.84 & 1.31 \\
\hline
\end{tabular}

However, the negative impact is larger during high stress, ranging from $-1.10 \%$ to $-3.67 \%$ for shock sizes one through four, compared to only $-0.47 \%$ to $-2.84 \%$. Thus, during financially calm periods, IP reacts more (less) strongly to positive (negative) FSI shocks - which is just the reverse from what we find for a financially distressed U.S. economy.

\subsection{Results for Selected EU Countries}

We now summarize the empirical findings for the five EU countries, the four largest euro zone economies German, France, Italy, and Spain plus, not belonging to the euro area, the UK. ${ }^{39}$ To do so, the discussion is based on the graphical presentations - analogous to Figure 8 - of the IP-growth responses due to FSI shocks of different sizes and signs, when applied at average high-and low-stress states. For each country, the stress-states are defined by their respective threshold estimates.

The response profiles for the five countries, shown in Figures 9-13, and that of the U.S. have, to a large extent, common patterns. But there are also a number of distinct features. Especially Spain, the country under investigation that has been most troubled during the euro crisis, exhibits a response pattern that is quite different.

Below, we first summarize our findings by looking at the response patters for the four possible

\footnotetext{
${ }^{39}$ The respective VAR and MRVAR estimation results are summarized in Table 3, reporting for each country the lag order, AICc values, estimated threshold values, and the number of observations associated with high- and low-stress regimes.
} 

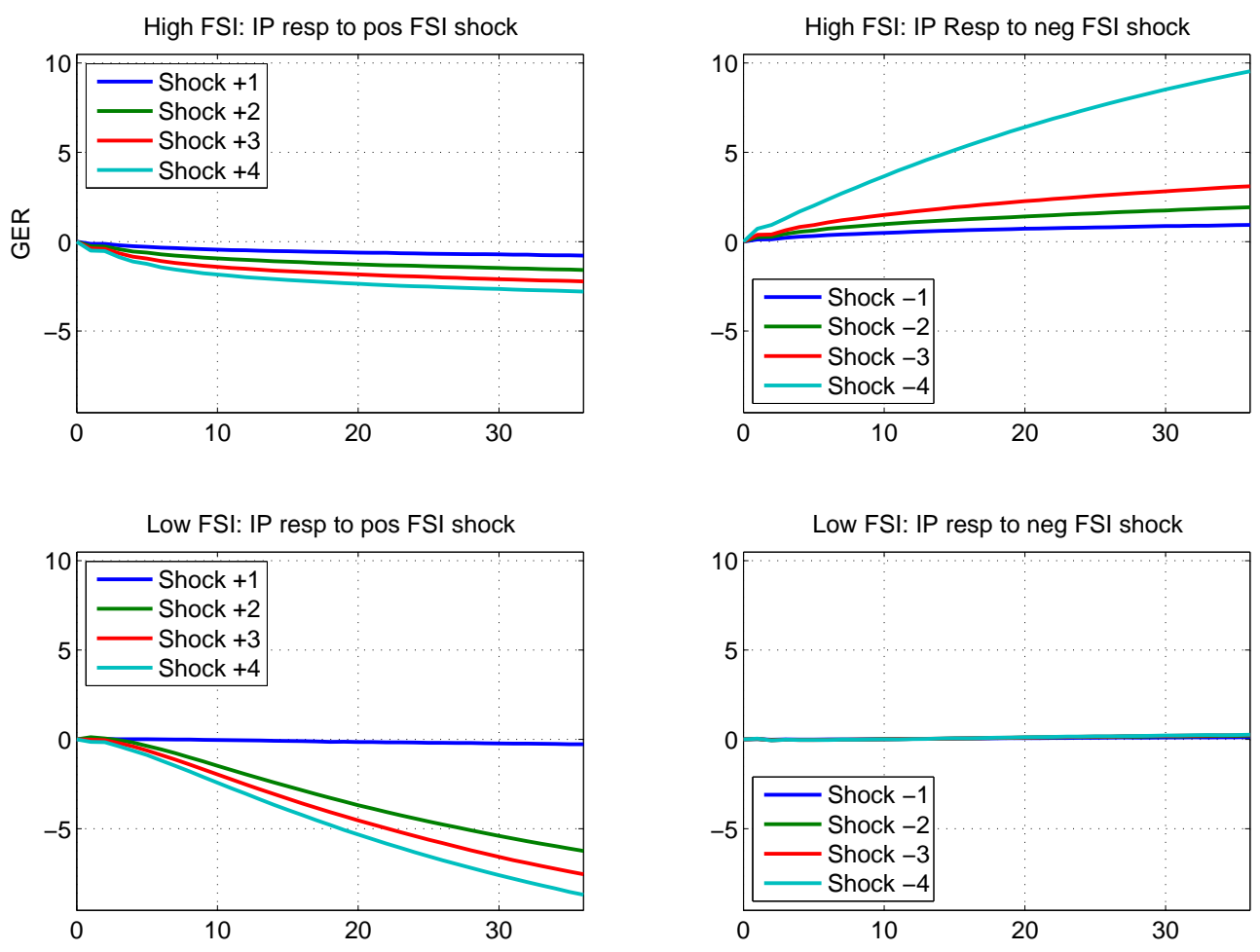

Figure 9: Cumulative MRVAR responses of German IP to negative (top) and positive (bottom) stress shocks in high- (left) and low-stress states (right)

combinations of shock signs and states of stress, letting shock size, again, assume values \pm 1 through \pm 4 .

Low stress and negative FSI shocks: The responses for this case are shown in the bottom, right graphs in Figures 9-13. For four of the five the EU countries, we find that, in state of low stress, IP remains virtually unaffected by FSI-reducing shocks. For shock sizes -1 though -4 , the cumulative IP responses are practically zero. I.e., the countries' real sectors react even less than is the case for the U.S., which exhibits small positive growth effects. In case of Spain, the response plots appear to be rather different, having opposite signs. Looking, however, at the magnitudes, the responses are close to zero-responses.

High stress and positive FSI shocks (top, left graphs): The response profiles from positive FSI shocks at financially distressed states of the economy are, except for Spain, for all countries very similar. We estimate weak negative IP effects, which, given the scaling of the responses by shock-size, increase in relative terms as the magnitude of the shock increase. In other words, larger shocks are more effective per unit of shock. The response magnitudes vary from country to country, with the U.S. exhibiting the largest impacts, followed by Germany, 

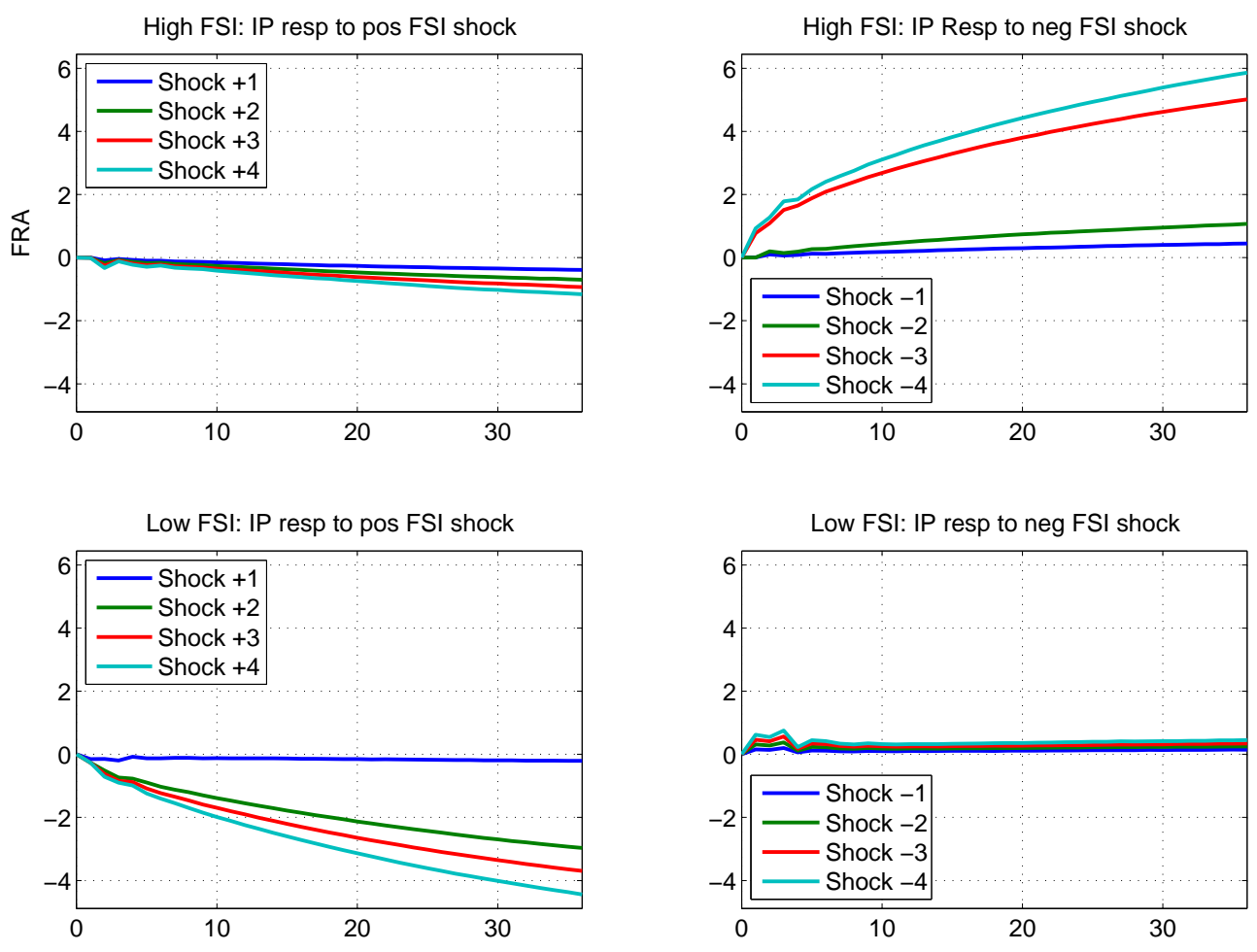

Figure 10: Cumulative MRVAR responses of French IP to negative (top) and positive (bottom) stress shocks in high- (left) and low-stress states (right)

the UK, Italy, and France. In the case of Spain, the responses have, again, the opposite sign but are extremely small.

High stress and negative FSI shocks (top, right graphs): Excepting Spain, we find for all countries a similar, positive IP response patterns for stress-reducing shocks in high-stress states. As in the case of the U.S., for three out of the four countries (France, Italy and the $\mathrm{UK}$ ), the relative response-impact jumps when moving from the two- to a three-unit shock. For Germany, the jump occurs when the shock size increases from three to four. This can be due to Germany's low FSI-threshold estimate, so that, in the average high-stress state, more sizeable, negative shocks are required to move the economy into the low-stress regime.

The response sizes vary from country to country. The U.S., Italy, the UK, and-disregarding the difference in the low-stress activation level-Germany display similarly large IP increases, when the low-stress regime does not tend to kick in, exceeding those of by France quite a bit. In case of large, negative four-unit shocks, U.S. IP reacts most, followed by Italy and Germany with about two third of the impact, and the UK and France with about only $40 \%$ of the impact estimated for the U.S. 

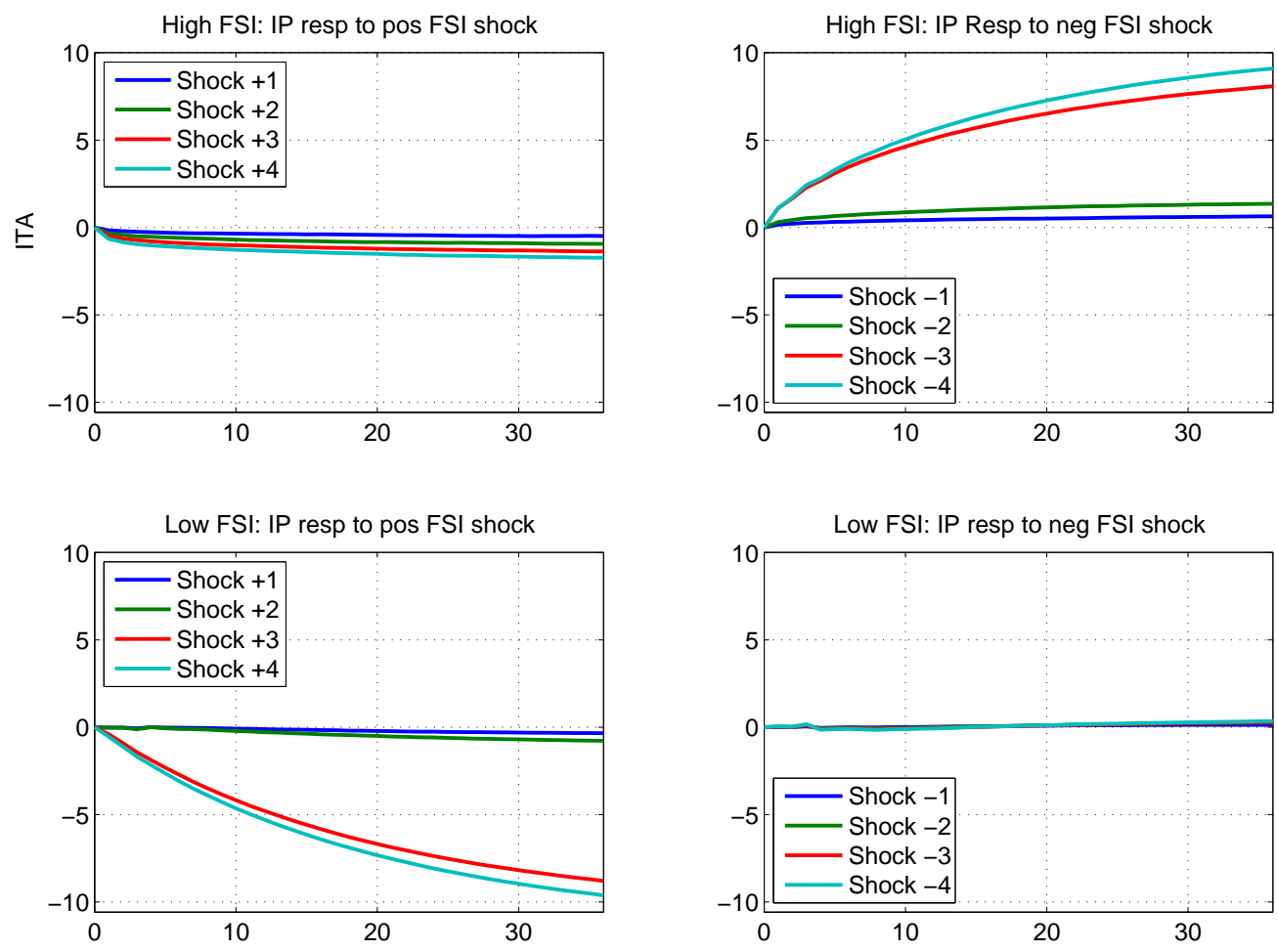

Figure 11: Cumulative MRVAR responses of Italian IP to negative (top) and positive (bottom) stress shocks in high- (left) and low-stress states (right)

Low stress and positive FSI shocks (bottom, right graphs): For all six countries, positive FSI shocks during low stress behave just the opposite of what we find in the reverse case with low stress and negative FSI shocks. The effects are, however, less pronounced than in the latter case. Also, the shock sizes, triggering large impacts, tend to differ.

\subsection{Relation to Similar Response Studies}

Regime-dependent response analyses, investigating the effects of a shock to financial stress economic activity using multi-regime approaches, have been conducted for the U.S. (Hakkio and Keeton, 2009; and Hubrich and Tetlow, 2011), for Germany (van Roye, 2012) and the euro area (Hollo et al. 2012). They come to the conclusion that a positive, one-unit stress shock in high-stress periods induces a more dramatic reduction in economic activity than during low-stress. These studies are, however, confined to the analysis of (positive) unit impulse shocks and do not investigate the sign- and size-dependence of the response profile as done here. For all countries (ignoring Spain), we also find that unit-shock responses have 

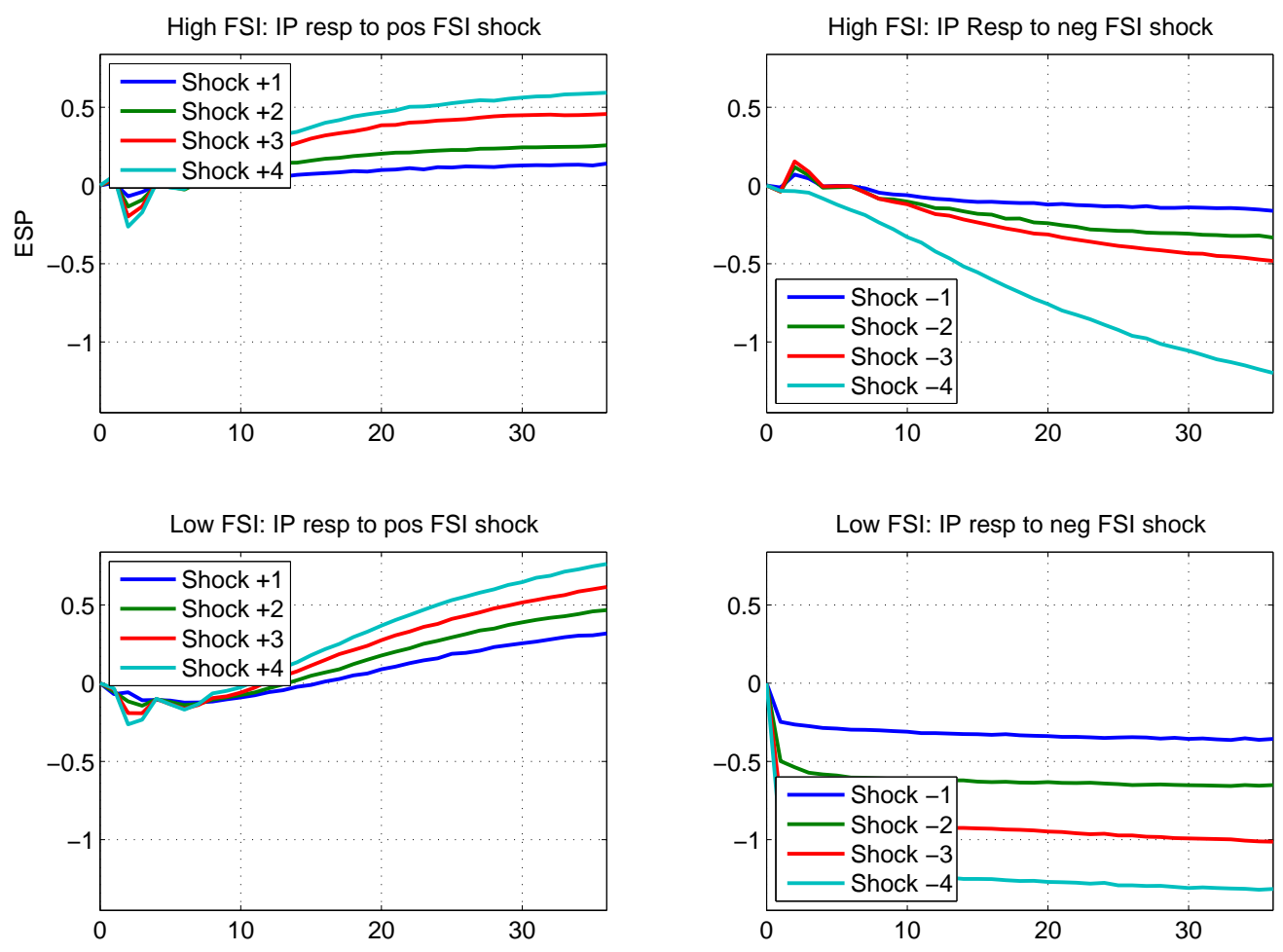

Figure 12: Cumulative MRVAR responses of Spanish IP to negative (top) and positive (bottom) stress shocks in high-(left) and low-stress states (right)

a more dramatic impact in high-stress than in low-stress regimes (see the left column in Table 5 and the unit-responses in the left panels in Figures 8-11 and 13).

Our results go beyond those in the studies mentioned above, as they imply that, as the shock size increases, this phenomenon will reverse. Large positive shocks will ultimately cause the financial system to move from the low-stress to the high-stress regime, causing IP cuts that are larger than experienced when the economy was already in a high-stress state.

In case of negative, i.e., stress reducing shocks, we obtain analogous results. Large stress reductions in a high-stress state can induce a switch to a low-stress regime and, accordingly, lead to large IP increases. On the other hand, a stress decrease during a calm period willin a two-regime setting - not result in a regime switch and, thus, leave IP more or less unaffected (see the right column in Table 5 and the responses in the right panels in Figures 8-11 and 13). 

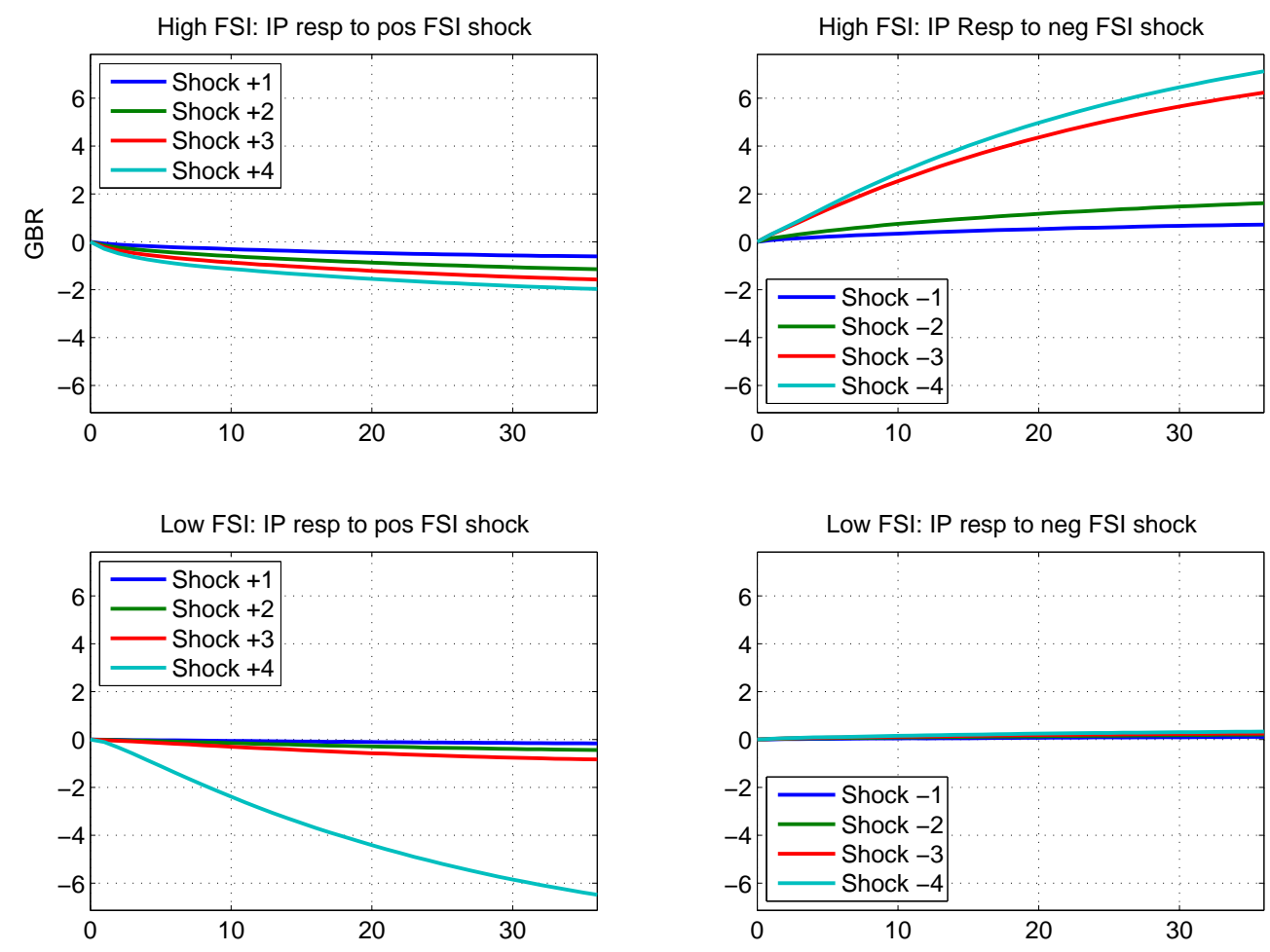

Figure 13: Cumulative MRVAR responses of UK IP to negative (top) and positive (bottom) stress shocks in high-(left) and low-stress states (right)

\subsection{Response Analysis and Policy Implications}

The response characteristics resulting from our MRVAR analysis have general implications for policy action. First, the effectiveness of monetary policy measures increases with the size of the measures; and the effectiveness increases over-proportionally. ${ }^{40}$ Thus, to calm extreme financial stress, extreme measures are called for in order to support real-sector economic activity. The Fed's recent drastic and "unconventional" quantitative-easing policies, designed to reduce the overall systemic risk, is in line with our findings, as only sufficiently large measures are likely to move a financially stressed economy into calmer waters. Second, the empirical results strongly suggest that the timing of policy actions affecting financial stress is very influential on their success. Stress-reducing measures applied during calm periods will have little real impact, relative to applying the same actions in a high-stress state.

Our findings are compatible with recent studies arguing that unconventional monetary policy

\footnotetext{
${ }^{40}$ However, as the - short-run and long-run - cost of policy measures will also increase disproportionately as their size increases, an appropriate balance needs to be found.
} 
is needed in a financially distressed economy, reflected by a sharp rise in credit spreads, which - rather than asset-price volatility - constitute the dominant component of the stress index (cf. Curdia and Woodford, 2009). Thus, not only a decrease in interest rates, but a reduction in credit spreads and financial stress as a whole is required to induce significant expansionary effects on real economic growth.

More generally, the empirical findings suggests that the stronger the global position of an economy in terms of output and share of world trade, the more autonomous are the financial stress effects directly impacting the economy. Moreover, in these economies, a large stress reduction in a high-stress period has a relatively more sizeable improvement on output. Yet the smaller the economies are, the more they are subjected to external dynamics and the spill over effects, which seem to significantly affect the consequences of domestic financialsector shocks. Moreover, as in the case of France, a larger public sector seems to act as a buffer against (positive and negative) stress shocks - possibly, as compared to Germany, at the expense of long-term growth.

The Spanish economy reacts very differently to shocks to the financial sector. Before the crisis, its economic growth paralleled that of Germany. But that was mainly driven by a booming housing sector, which seems to have insulated Spain from external effects. After the - yet to be overcome-collapse of the real-estate sector, the economy has not recovered, as it has the U.S. and Germany, and longer adjustment time may be needed to regain diversification and competitiveness.

\section{Conclusions}

Most severe economic crises have led to a meltdown of the banking sector, and-regardless of the crisis' origin - the banking sector has typically aggravated the economic downturn. To better understand the linkages between economic activity and financial stress, first, we have

developed a theoretical model describing the dynamics of the banking sector's instability when being exposed to shocks in asset price, credit spread and financial stress in general. Then, in a six-country study, using nonlinear, multi-regime VARs and monthly data on industrial production and a financial-stress index provided by the IMF, we have examined real-sector and financial-sector interactions.

Our theoretical model implies that unfavorable credit spreads, high leverage ratios and excessive (bonus) payouts play an important role for the deterioration of the banks' balance sheets and the stability of the banking sector - or the lack thereof. In the presence of large 
credit spreads, high leveraging and large payouts, sever adverse shocks can induce instabilities, whereas, for smaller shocks, the system exhibits mean reversion. In contrast to previous studies of the financial accelerator, which postulate a locally amplifying but globally stable and mean reverting system, our model admits downward instability as suggested in Brunnermeier and Sannikov (2010).

The empirical findings reveal that the effects of financial-sector shocks are state-dependent and that, in addition, the relative effectiveness of the shocks depends on the sign and size of the shocks. Although there is some heterogeneity between countries in the sense that IP responses to stress-shocks are larger in the bigger economies, such as Germany and the U.S., there are quite common features: Large positive financial-sector shocks during states of low stress have less of a contractionary effect than in a high stress regime; and large stress reductions lead to stronger expansionary effects in high- than in low-stress regimes. This holds for five out of the six countries studied, with Spain being the sole exception.

In terms of policy implications, our results strongly suggest that in times of severe financial crises that affect the real sector, potent "unconventional" monetary policy, which calm financial markets, can be a promising strategy. However, both timing and intensity of policy actions matter.

\section{References}

[1] Adrian, T., A. Moench, and H.S. Shin (2010), "Macro Risk Premium and Intermediary Balance Sheet Quantities," Federal Reserve Bank of New York, Staff Report No. 428

[2] Becker, S., L. Gruene, and W. Semmler (2007), "Comparing Second Order Approximation with Dynamic Programming," Computational Economics, 30, 65-91.

[3] Bernanke, B., M. Gertler, and S. Gilchrist (1999), "The Financial Accelerator in a Quantitative Business Cycle Framework," in J. Taylor and M. Woodford (eds), Handbook of Macroeconomics, Amsterdam, North-Holland.

[4] Bruno, R. and R.W. Dimand (2009), "The Corridor of Stability in Tobin's Keynesian Model of Recession and Depression," International Journal of Applied Economics \& Econometrics, XVII, 17-25.

[5] Brunnermeier, M. (2009), "Deciphering the Liquidity and Credit Crunch 2007-2008," Journal of Economic Perspectives, 23, 77-100.

[6] Brunnermeier, M. and Y. Sannikov (2010), "A Macroeconomic Model with the Financial Sector," manuscript, Dept. of Economics, Princeton University; see also their version (2011). 
[7] Burnham, K.P. and D.R. Anderson (1998), Model Selection and Inference: A Practical Information-Theoretical Approach New York: Springer-Verlag.

[8] Caballero, R. and A. Krishnamurtha (2008), "Global Imbalances and Financial Fragility," http://econ-www.mit.edu/files/366, MIT.

[9] Cardarelli, R., S. Elekdag, and S. Lall (2011), "Financial Stress and Economic Contractions," Journal of Financial Stability, 7, 78-97.

[10] Christensen, I. and A. Dib (2008), "The Financial Accelerator in an Estimated New Keynesian Model," Review of Economic Dynamics, 11, 155-178.

[11] Cochrane, J. (2011), "Presidential Address: Discount Rates," manuscript, University of Chicago.

[12] Curdia, V. and M. Woodord (2009), "Credit Spreads and Monetary Policy," Paper presented at the Conference on Financial Market and Monetary Policy, Federal Reserve Board, June 5-6.

[13] Davig, T. and C. Hakkio (2010), "What is the Effect of FInancial Stress on Economic Activity?," Economic Review, Federal Reserve Bank of Kansas City, Second Quarter, $35-62$.

[14] Del Negro, M., G. Eggersson, A. Ferrero, and N. Kiyotaki (2011), "The Great Escape: A Quantitative Evaluation of the Fed's Non-Standard Policies," Federal Reserve Bank of New York Staff Report 520.

[15] Dimand, R. W. (2005), "Fisher, Keynes, and the Corridor of Stability," American Journal of Economics and Sociology, 64, 185-199.

[16] Ehrmann, M., M. Ellison and N. Valla (2003), "Regime-dependent Impulse Response Functions in a Markov-switching Vector Autoregressive Model," Economic Letters, 78, 295-299.

[17] Ernst, E. and W. Semmler (2010), "Global Dynamics in a Model with Search and Matching in Labor and Capital Markets," Journal of Economic Dynamics and Control, 34, 1651-1679.

[18] Ernst, E. S. Mittnik, and W. Semmler (2010), "Interaction of Labor and Credit Market Frictions: A Theoretical and Empirical Analysis," paper presented at the Winter Meeting of the Econometric Society, Atlanta, January 2010.

[19] Financial Stability Board (2009), "FSB Principles for Sound Compensation PracticesImplementation Standards," 25. September 2009.

[20] Geanakoplos, J. (2010), "The Leverage Cycle," Cowles Foundation Paper No. 1304.

[21] Geanakoplos, J. and J. Farmer (2009), "The Virtues and Vices of Equilibrium and the Future of Financial Economics," Complexity 14, 11-38. 
[22] Geneva Report on the World Economy 11 (2009), "Fundamental Principles of Financial Regulations," International Center for Monetary and Banking Studies.

[23] Gilchrist, S., A. Ortiz, and S. Zagrajsek (2009), "Credit Risk and the Macroeconomy: Evidence from an Estimated DSGE Model," manuscript, Department of Economics, Boston University.

[24] Gorton, G.B. (2009), "Information, Liquidity, and the (Ongoing) Panic of 2007," NBER Working Paper No. 14649.

[25] Gorton, G.B. (2010), "Slapped by the Invisible Hand: The Panic of 2007," Oxford: Oxford University Press.

[26] Gruene, L. and W. Semmler (2004), "Using Dynamic Programming with Adaptive Grid Scheme for Optimal Control Problems in Economics," Journal of Economic Dynamics and Control, 28, 2427-2456.

[27] Gruene, L. and W. Semmler (2005), "Default Risk, Asset Pricing, and Debt Control," Journal of Financial Econometrics 2005 3, 79-106.

[28] Gruene, L. and W. Semmler (2008), "Asset Pricing with Loss Aversion," Journal of Economic Dynamics and Control, 32, 3253-3274.

[29] Hakkio, C.S. and W.R. Keeton (2009), "Financial Stress: What Is It, How Can It Be Measured, and Why Does It Matter?" Federal Reserve Bank of Kansas City, Economic Review, Second Quarter, 5-50.

[30] Hall, E.R. (2010), Forward Looking Decision Making, Princeton: Princeton University Press.

[31] Hamilton, J.D. (1989), "A New Approach to the Economic Analysis of Nonstationary Time Series and the Business Cycle," Econometrica 57, 357-384.

[32] Hansen, B.E. (2000), "Sample Splitting and Threshold Estimation," Econometrica 68, 575-603.

[33] Hatzius, J., P. Hooper, F. Mishkin, K. Schoenholtz, and M.W. Watson (2010), Financial Condition Indexes: A Fresh Look after the Financial Crisis," NBER Working Paper No. 16150.

[34] He, Z. and A. Krishnamurthy (2008), "Intermediary Asset Pricing," manuscript, University of Chicago.

[35] Hollo, D., M. Kremer and M. Lo Duca (2012), "CISS-A Composite Indicator of Systemic Stress in the Financial System," Working Paper, No. 1426, European Central Bank.

[36] Hubrich, K. and R.J. Tetlow (2011), "Financial Stress and Economic Dynamics: The Transmission of Crises," unpublished working paper European Central Bank. 
[37] Hsiao, C.-Y. and W. Semmler (2009), "Harmonic Fitting for Long Run Economic Data, manuscript, www.newschool.edu/nssr/cem (there: "Financial Market")

[38] Illing, M. and Y. Liu (2006), "Measuring Financial Stress in a Developed Country: An Application to Canada," Journal of Financial Stability, 2, 243-265.

[39] Kindleberger, C. and R. Aliber (2005), Manias, Panics, and Crashes: A History of Financial Crises, 5th ed., Wiley.

[40] Kliesen, K.L., M.T. Owyang and E.K. Vermann (2012), "Disentangling Diverse Measures: A Survey of Financial Stress Indexes," Federal Reserve Bank of St. Louis Review, September/October 2012, 94, 369-397.

[41] Koop, G., M. Pesaran and S. Potter (1996), "Impulse Responses in Nonlinear Multivariate Models," Journal of Econometrics, 74, 119-147.

[42] Mallick, S. K. and R. M. Sousa (2011), "The Real Effects of Financial Stress in the Euro Zone," NIPE Working Paper 12/2011, Department of Economics and Economic Policy Research Unit (NIPE), University of Minho.

[43] Merton, R.C. (1974), "On the Pricing of Corporate Debt: The Risk Structure of the Interest Rate," Journal of Finance, 2, 449-470.

[44] Minsky, H.P. (1975), John Maynard Keynes, New York: Columbia University Press.

[45] Minsky, H.P. (1982), Can it Happen again?, Armonk: ME Sharpe.

[46] Mittnik, S. and W. Semmler (2012), "Regime Dependence of the Fiscal Multiplier," Journal of Economic Behavior \& Organization, 83, 502-522.

[47] Mittnik, S. and P. Zadrozny (1993), "Asymptotic Distributions of Impulse Responses, Step Responses, and Variance Decompositions of Estimated Linear Dynamic Models," Econometrica, 61, 857-887.

[48] Monnin, P. and T. Jokipii (2010), "The Impact of Banking Instability on the Real Economy," Working Paper 2010-5, Swiss National Bank.

[49] OECD (2012), OECD Monthly Economic Indicators.

[50] Reinhart. C. and K.S. Rogoff (2009), This Time Is Different: Eight Centuries of Financial Folly, Princeton: Princeton University Press.

[51] van Roye, B. (2012), "Financial Stress and Economic Activity in Germany," unpublished working paper, Kiel Institute for World Economy.

[52] Schinasi, G.J. (2005), "Preserving Financial Stability," International Monetary Fund, Economic Issues, 36 .

[53] Semmler, W. and L. Bernard (2012), "Boom-Bust Cycles: Leveraging, Complex Securities, and Asset Prices," Journal of Economic Behavior and Organization, 81, 442-465. 
[54] Semmler, W., L. Gruene, and L. C. Oehrlein (2009), "Dynamic Consumption and Portfolio Decisions with Time Varying Asset Returns," Journal of Wealth Management, 12, $21-47$.

[55] Tong, H. (1978), "On a Threshold Model," in: Pattern Recognition and Signal Processing, edited by C. H. Chen, Amsterdam: Kluwer.

[56] Tong, H. (1983), Threshold Models in Non-linear Time Series Analysis, New York: Springer-Verlag.

[57] Tsay, R.S. (1998), "Testing and Modelling Multivariate Threshold Models," Journal of the American Statistical Association, 93, 1188-1202.

[58] Wong, C.S. and W.K. Li (1998), "A Note on the Corrected Akaike Information Criterion for Threshold Autoregressive Models," Journal of Time Series Analysis, 19, 113-124. 


\section{Appendix: Estimating Time Varying Credit Spreads}

The calibration of the theoretical model in Section 3 is based on Hsiao and Semmler (2009) and applies Fast Fourier Transformation (FFT) to German FSI as a proxy of the timevarying default risk and credit cost. Estimating the periodic components by fitting linear combinations of sine-cosine functions, i.e.,

$$
x_{t}=\sum_{i=1}^{n}\left(a_{i} \sin \left(\frac{2 \pi}{\tau_{i}}\left(t-t_{0}\right)\right)+b_{i} \cos \left(\frac{2 \pi}{\tau_{i}}\left(t-t_{0}\right)\right)\right) .
$$

we obtain the coefficients reported in 6 . The estimates in Tabel 6 are then used for the DP solution. For details see Semmler et al. (2009). The close fit of (14) is illustrated in Figure 14.

Table 6: Coefficients of the harmonic fit of the real bond yield in (14)

\begin{tabular}{|c|r|r|r|r|r|r|}
\hline$i=$ & 1 & 2 & 3 & 4 & 5 & 6 \\
\hline$\tau_{i}$ (month) & 120 & 36 & 48 & 60 & 96 & 75 \\
\hline$a_{i}$ & -0.263 & 0.0854 & 1.1592 & 0.1483 & 1.9493 & 0.1523 \\
\hline$b_{i}$ & 0.0445 & -0.0837 & 1.2705 & 0.6065 & 1.6699 & 1.2001 \\
\hline
\end{tabular}

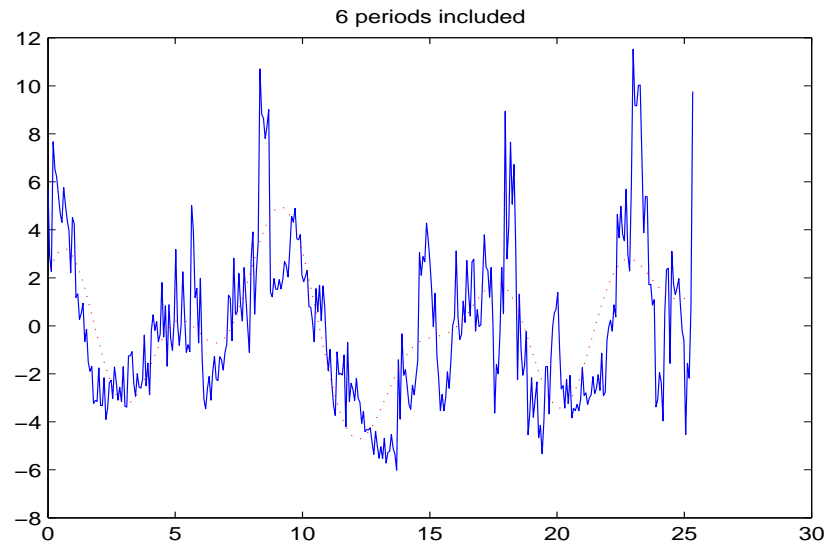

Figure 14: Actual and fitted FSI series for Germany 


\section{SFB 649 Discussion Paper Series 2013}

For a complete list of Discussion Papers published by the SFB 649, please visit http://sfb649. wiwi.hu-berlin.de.

001 "Functional Data Analysis of Generalized Quantile Regressions" by Mengmeng Guo, Lhan Zhou, Jianhua Z. Huang and Wolfgang Karl Härdle, January 2013.

002 "Statistical properties and stability of ratings in a subset of US firms" by Alexander B. Matthies, January 2013.

003 "Empirical Research on Corporate Credit-Ratings: A Literature Review" by Alexander B. Matthies, J anuary 2013.

004 "Preference for Randomization: Empirical and Experimental Evidence" by Nadja Dwenger, Dorothea Kübler and Georg Weizsäcker, January 2013.

005 "Pricing Rainfall Derivatives at the CME" by Brenda López Cabrera, Martin Odening and Matthias Ritter, January 2013.

006 "Inference for Multi-Dimensional High-Frequency Data: Equivalence of Methods, Central Limit Theorems, and an Application to Conditional Independence Testing" by Markus Bibinger and Per A. Mykland, January 2013.

007 "Crossing Network versus Dealer Market: Unique Equilibrium in the Allocation of Order Flow" by Jutta Dönges, Frank Heinemann and Tijmen R. Daniëls, January 2013.

008 "Forecasting systemic impact in financial networks" by Nikolaus Hautsch, Julia Schaumburg and Melanie Schienle, January 2013.

009 "I'll do it by myself as I knew it all along': On the failure of hindsightbiased principals to delegate optimally" by David Danz, Frank Hüber, Dorothea Kübler, Lydia Mechtenberg and Julia Schmid, January 2013.

010 "Composite Quantile Regression for the Single-Index Model" by Yan Fan, Wolfgang Karl Härdle, Weining Wang and Lixing Zhu, February 2013.

011 "The Real Consequences of Financial Stress" by Stefan Mittnik and Willi Semmler, February 2013. 